\title{
A Multilevel Inverter Bridge Control Structure with Energy Storage Using Model Predictive Control for Flat Systems
}

\author{
Paolo Mercorelli \\ Leuphana University of Lueneburg, Institute of Product and Process Innovation, Volgershall 1, 21339 Lueneburg, Germany \\ Correspondence should be addressed to Paolo Mercorelli; mercorelli@uni.leuphana.de
}

Received 5 September 2012; Accepted 30 December 2012

Academic Editor: Claudio Mazzotti

Copyright ( 2013 Paolo Mercorelli. This is an open access article distributed under the Creative Commons Attribution License, which permits unrestricted use, distribution, and reproduction in any medium, provided the original work is properly cited.

\begin{abstract}
The paper presents a novel technique to control the current of an electromagnetic linear actuator fed by a multilevel IGBT voltage inverter with dynamic energy storage. The technique uses a "cascade model predictive control (MPC)," which consists of two MPCs. A predictive control of the trajectory position predicts the optimal current, which is considered to be the desired current for the second MPC controller in which a hysteresis control technique is also integrated. Energy is stored in a capacitor using energy recovery. The current MPC can handle a capacitor voltage higher than the source voltage to guarantee high dynamic current and disturbance compensation. The main contribution of this paper is the design of an optimal control structure that guarantees a capacitor recharge. In this context, the approach is quite new and can represent a general emerging approach allowing to reduce the complexity of the new generation of inverters and, in the meantime, to guarantee precision and acceptable switching frequency. The proposed technique shows very promising results through simulations with real actuator data in an innovative transportation technology.
\end{abstract}

\section{Introduction and Motivation}

The performance of a multilevel inverter is better than that of a classical inverter. The total harmonic distortion of a classical inverter is very high; that is, the total harmonic distortion for a multilevel inverter is low. This topic has become the focus of a significant amount of research. One study has simulated and implemented a multilevel inverterfed induction motor drive [1]. The output harmonic content is reduced by using a multilevel inverter. In a symmetrical circuit, the voltage and power increase as the number of levels in the inverter increases. The switching angle for the pulse is selected to reduce the harmonic distortion. This drive system has several advantages, including reduced total harmonic distortion and higher torque. A normal neutral point potential stabilization technique using the output current polarity has been proposed [2]. The neutral point potential balancing algorithm for three-level neutral point clamped inverters using an analytically injected zero-sequence voltage has been developed [3]. Modulation schemes to eliminate common mode voltage in multilevel inverter topology have been suggested [4]. A generalized multilevel inverter topology with self-voltage balancing has also been suggested [5]. A survey of topologies, control, and applications of multilevel inverters has been published [6]. A digital modulation technique for dual three-phase alternating current (AC) machines has been presented [7]. A space vector pulse-width modulation (PWM) technique for a dual three-phase AC machine and its digital signal processor (DSP) implementation has been presented [8]. Practical medium voltage converter topologies for high power applications have been described previously [911]. Industrial topologies have been presented [12]. Different pulse-width modulation techniques for symmetrical cascade inverters with high and fundamental switching frequency have been shown, for instance, in $[13,14]$. An improvement in terms of efficiency of the converter is presented in [15] where the authors use different DC sources to reduce the switching losses. More recently in [16], the authors proposed a novel $\mathrm{H}$-bridge multilevel pulse modulation converter topology in which the structure is based on a series connection of highvoltage diode-clamped inverter and low-voltage conventional inverter. The present work implements a controlled multilevel 
inverter feeding an electromagnetic actuator. In particular, two MPCs in cascade structure are presented to control fivelevel inverter electromagnetic actuators which are becoming increasingly important in many industrial applications. Thanks to recent progress in permanent-magnet technology, very compact and high-power electromagnetic actuators are now available. Particularly in automotive systems, these actuators have often replaced conventional mechanical components due to their high efficiency, excellent dynamic behavior, and control flexibility; thus, mechatronics is one of the most notable innovative fields in the automobile industry. A recent design of such an actuator (e.g., [17]) considers optimizing with respect to dimensions and forces. Nevertheless, practical tests show that this actuator structure is not always effective for a large variety of applications because a complex control structure is needed to control such a valve [18]. Recently, for instance, a new type of electromagnetic valve drive system has been proposed and described [19]. This paper presents the control design for a novel permanent-magnet linear valve actuator for use in a variable engine control to allow short-stroke and high-dynamic motions. In a linear actuator, the electromagnetic force is totally independent of the constrained motion. Specifically, the electromagnetic force is parallel to the magnetic axis, and thus it is orthogonal to the constrained motion. These performance characteristics make this type of actuator an excellent candidate in applications requiring both high precision and high-load capacity. In order to obtain an actuator structure that could be easily controlled, various linear designs with different permanent magnet actuator topologies using $\mathrm{NdFeB}$ magnets were considered. In particular, the objective of this paper is to design a controller structure consisting of

(i) a flatness-based feedforward control,

(ii) a multilevel inverter configuration,

(iii) a cascade MPC structure based on optimized energetic functions to control the proposed multilevel inverter with storage energy.

An important aspect of this approach is the use of geometric system properties, such as the differential flatness needed to track the desired trajectories. In this context, recently published research results have been considered (e.g., [20]) in which the author proposed an interesting method to integrate MPC and a feedforward flatness control. The second part of the paper shows the structure of the cascade MPC defined above. For trajectory-based motion cycles, there is usually a need to control the actuator current separately. The reference value for the actuator current is normally generated by the speed or position controller in an outer control loop based on the desired speed or position profiles. The current control is used to provide the force or torque required for the desired motion quickly and precisely. Generally, three main techniques are employed for current control of a voltagesource inverter (VSI):

(i) closed loop control (e.g., PID control) using pulsewidth modulated terminal voltages [21], (ii) hysteresis control techniques [22, 23],

(iii) predictive current control [24-26].

The PWM technique is currently the most popular method for an inverter current control. The main advantage of PWM techniques is that the inverter switches operate at a fixed frequency, and hardware- or software-based standard modulators are available as industrial products (e.g., onboard microcontrollers). A staggered space vector modulation technique applicable to three-phase cascaded voltagesource inverter topologies has also been demonstrated with a single-phase cascaded voltage-source inverter that uses a series connection of insulated gate bipolar transistor (IGBT) $\mathrm{H}$-bridge modules with isolated DC buses [27]. Among various modulation techniques for a multilevel inverter, the space vector pulse width modulation (SVPWM) is widely used. However, implementing the SVPWM for a multilevel inverter is complicated because it is difficult to determine the location of the reference vector, calculate on times, and determine and select switching states. A previous paper has proposed a general SVPWM algorithm for multilevel inverters based on standard two-level SVPWM. However, the system response is affected by the stability requirements of the feedback loop, which also depend on load parameters; moreover, appreciable phase lag may arise even in the steady state. Recently, many studies have focused on solving these problems (e.g., $[28,29])$ of multilevel inverter modules with independent control of the phase angle and magnitude of the output voltage [29]. Control and new power bridge structures have been studied. Very recent works have presented a novel bridge structure $[30,31]$. In both structures, capacitors are used but not recharged. In particular, an MPC strategy is proposed for a three-phase power bridge [30]. Hysteresis current control has a fast response and a good accuracy. It can be implemented with a simple hardware structure, and, in many cases, it does not require any knowledge of load parameters. However, it can sometimes cause very high switching frequencies or, if the maximum switching frequency is limited, the current waveform may vary widely and the current peaks may appreciably exceed the hysteresis band depending on the operation conditions and load parameters. Conventional predictive current control uses a simple gradient model to predict load current in vector space and determine the proper switching voltage vector based on the one-step prediction [24-26]. However, no feedback loop is applied to compensate for model uncertainties. To overcome the disadvantages of the mentioned methods, this study develops a novel approach that combines hysteresis control with a model predictive control (MPC) strategy. The proposed control system integrates flatness and two cascade MPCs. The first MPC generates an optimal desired current by minimizing position error. The second MPC considers this optimal desired current to be the reference signal to find an optimal switching law in combination with the hysteresis control. A special energy storage and charging circuit was designed to provide multilevel voltages for an effective current control. By applying the proper voltage level, which was determined by the MPC strategy, to the actuator, dynamic current changes and small current ripples 


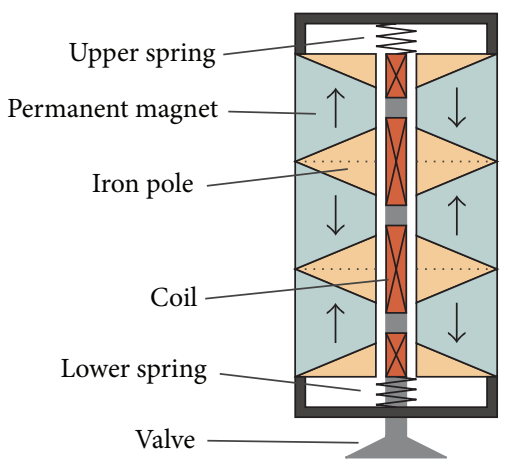

FIGURE 1: Cross-section of the perpendicular linear actuator.

are possible in spite of relatively low switching frequencies. A recent work [32] proposes "fast" algorithms based on computing the formulated problems in parallel. In fact, the optimization technique uses subsets of the state subspace offline and then optimizes them in parallel. In this paper, a cascade structure of MPCs is utilized to control a multilevel inverter. Two different optimization techniques are presented as well. The main contribution of the paper is the optimal control structure, which also guarantees that the capacitor recharges. In this context, the approach is quite new. The paper is organized in the following way.

Section 2 describes the model. In Section 3, the flatness property of the system is shown. In Section 4, the general MPC goal is defined and the main idea of using a cascade positional MPC followed by a current MPC is explained. In Section 5, a positional MPC around the desired trajectory is proposed. Section 6 is devoted to analyzing and optimizing the current MPC. The simulation results and some concluding remarks end the paper.

\section{Description of the Physical Systems}

The electromagnetic actuator is depicted in Figure 1. The structure of this actuator is a moving coil; thus, the coils are mounted on the upper part of the stem of the valve. The moving valve was connected to the power system to feed the coil with two normal cables with fix contacts. This arrangement is possible because of the short stroke to be covered $(8 \mathrm{~mm})$. The valve can be modeled mathematically in the following way:

$$
\begin{gathered}
\frac{\partial i_{\text {coil }}(t)}{\partial t}=-\frac{R_{\text {coil }}}{L_{\text {coil }}} i_{\text {coil }}(t)+\frac{U_{\text {in }}(t)-u_{q}\left(i_{\text {coil }}(t), s(t)\right)}{L_{\text {coil }}}, \\
\frac{\partial s(t)}{\partial t}=v(t) \\
\frac{\partial v(t)}{\partial t}=\frac{D_{g}\left(i_{\text {coil }}(t), s(t)\right)}{m} i_{\text {coil }}(t) \\
+\frac{-k_{d} v(t)-k_{f} s(t)+F_{0}(t)}{m}
\end{gathered}
$$

where

$$
\begin{aligned}
& D_{g}\left(i_{\text {coil }}(t), s(t)\right)=\frac{\Phi_{h}\left(i_{\text {coil }}(t), s(t)\right) l_{\text {coil }}}{A_{\text {coil }}}, \\
& u_{q}\left(i_{\text {coil }}(t), s(t)\right)=D_{g}\left(i_{\text {coil }}(t), s(t)\right) v(t) .
\end{aligned}
$$

It is important to note that $D_{g}\left(i_{\text {coil }}(t), s(t)\right)>0$ for all $i_{\text {coil }}(t)$ and for all $s(t) . R_{\text {coil }}$ and $L_{\text {coil }}$ are the resistance and the inductance of the coil windings; $U_{\text {in }}(t)$ is the input voltage; $u_{q}(t)$ is the induced back voltage; $\Phi_{h}$ is the magnetic flux penetrating the coil; $i_{\text {coil }}(t)$ is the coil current; $l_{\text {coil }}$ is the coil length. $s(t), v(t)$, and $m$ are the position, velocity, and mass of the actuator, respectively, while $k_{d} v(t), k_{f} s(t)$, and $F_{0}(t)$ represent the viscose friction, the total spring force, and the disturbing force acting on the valve. Equation (1) represents the electrical system of the actuator. Both (2) and (3) describe the mechanical behavior of the actuator, and (2) and (4) also represent the magnetic system. In particular, the following expression

$$
F_{L}(t)=D_{g}\left(i_{\text {coil }}(t), s(t)\right) i_{\text {coil }}(t)
$$

describes the Lorentz force generated by the actuator. Essentially, the magnetic flux, generated by the permanent magnets, has two components in the air gap: (1) the main flux $\Phi_{h}\left(i_{\text {coil }}(t)\right)$, which does not depend on the displacement of the mover and is responsible for the Lorentz force and the induced back voltage, and (2) the leakage flux $\Phi_{\sigma}\left(i_{\text {coil }}(t), s(t)\right)$, which disperses around the coil and does not contribute to the electromagnetic force and induced back voltage:

$$
\Phi_{h}\left(i_{\text {coil }}(t)\right)+\Phi_{\sigma}\left(i_{\text {coil }}(t), s(t)\right)=\Phi_{\mathrm{PM}}\left(i_{\text {coil }}(t)\right) .
$$

However, due to the special actuator design, the leakage flux is almost equal to zero. Thus, it is possible to conclude

$$
D_{g}\left(i_{\text {coil }}(t), s(t)\right) \approx D_{g}\left(i_{\text {coil }}(t)\right)=\frac{\Phi_{\mathrm{PM}}\left(i_{\text {coil }}(t)\right) l_{\text {coil }}}{A_{\text {coil }}} .
$$

\section{Differential Flatness of the System}

Roughly speaking, a system is differentially flat if it is possible to find a set of outputs equal in number to the number of inputs such that all states and inputs are expressed in terms of those outputs and their derivatives. To be more precise, if the system has state variables $\mathbf{x} \in \mathfrak{R}^{n}$ and inputs $\mathbf{u} \in \mathfrak{R}^{m}$, then the system is flat if the outputs $\mathbf{y} \in \mathfrak{R}^{m}$ have the following form:

$$
\begin{gathered}
\mathbf{y}=\mathbf{y}\left(\mathbf{x}, \mathbf{u}, \dot{\mathbf{u}}, \ldots, \mathbf{u}^{(p)}\right), \\
\mathbf{x}=\mathbf{x}\left(\mathbf{y}, \dot{\mathbf{y}}, \ldots, \mathbf{y}^{(q)}\right) ; \quad \mathbf{u}=\mathbf{u}\left(\mathbf{y}, \dot{\mathbf{y}}, \ldots, \mathbf{y}^{(q+1)}\right) .
\end{gathered}
$$

Differentially flat systems are especially interesting in situations in which explicit trajectory tracking is required. Because the behavior of the flat system is given by the flat output, it is possible to plan trajectories in output space and then map them to the appropriate inputs. Concerning the 


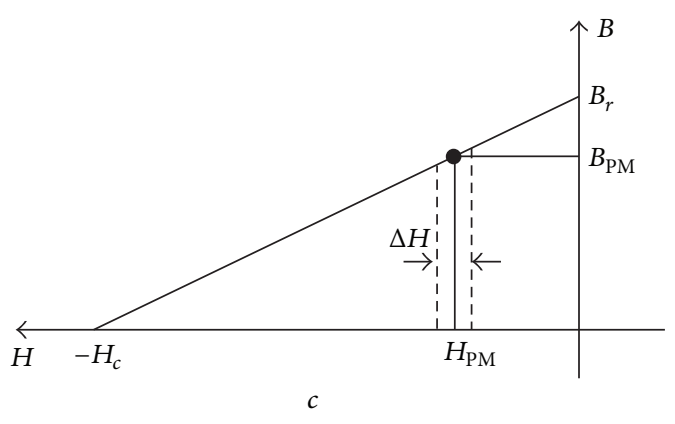

FIgURE 2: Permanent-magnet demagnetization curve.

flat output, for dating neither the necessary and sufficient condition nor a general method for the determination of the flat output has been provided. Typically, a flat output is guessed, and Definitions (8) and (9) are used to verify that the chosen output is flat. Once the system is proven to be differentially flat, the basic approach of two degrees of freedom controller design consists of two steps: first, separating the nonlinear controller synthesis problem into designing a feasible feedforward controlled trajectory for the nominal model of the system and second regulating that trajectory using controllers, that guarantee robust performance in the presence of uncertainties and disturbances. To explain the meaning of flatness intuitively, it is adequate to consider a system to be flat when the dynamic of at least one output is "visible" from the state and the input of the system; thus, there is at least one output that can be functionally controlled by the inputs as well by the states.

Now the first step is to show that our model represented in (1), (2), and (3) is flat. If the position $s$ of the moving part of the actuator is chosen as "guessed output," then

$$
\begin{gathered}
y(t)=s(t) \Longrightarrow s(t)=y(t) \\
\dot{s}(t)=\dot{y}(t) \Longrightarrow v(t)=\dot{y}(t), \\
i_{\text {coil }}(t) D_{g}\left(i_{\text {coil }}(t)\right)=m\left(\frac{k_{d}}{m} v(t)+\frac{k_{f}}{m} s(t)+\frac{\partial v(t)}{\partial t}\right), \\
U_{\text {in }}(t)=L_{\text {coil }} \frac{\partial i_{\text {coil }}(t)}{\partial t}+R_{\text {coil }} i_{\text {coil }}(t)+D_{g}\left(i_{\text {coil }}(t)\right) v(t) .
\end{gathered}
$$

To verify the flatness property it is necessary to look at (13). As evident from (7), $D_{g}\left(i_{\text {coil }}(t)\right)$ is proportional to the flux coupled with the permanent magnets which is again proportional to the flux density $B_{\mathrm{PM}}$. The operating point $\left(B_{\mathrm{PM}}, H_{\mathrm{PM}}\right)$ of the permanent magnets is mainly determined by the magnet geometry and the demagnetization curve (Figure 2). The coil current only changes the field strength around the operating point $(\Delta H)$ algebraically. An exact analytical expression between $\Delta H$ and $i_{\text {coil }}(t)$ is very difficult to be derived because it also depends on the saturation level of the iron parts. However, a numerical solution exists. In other

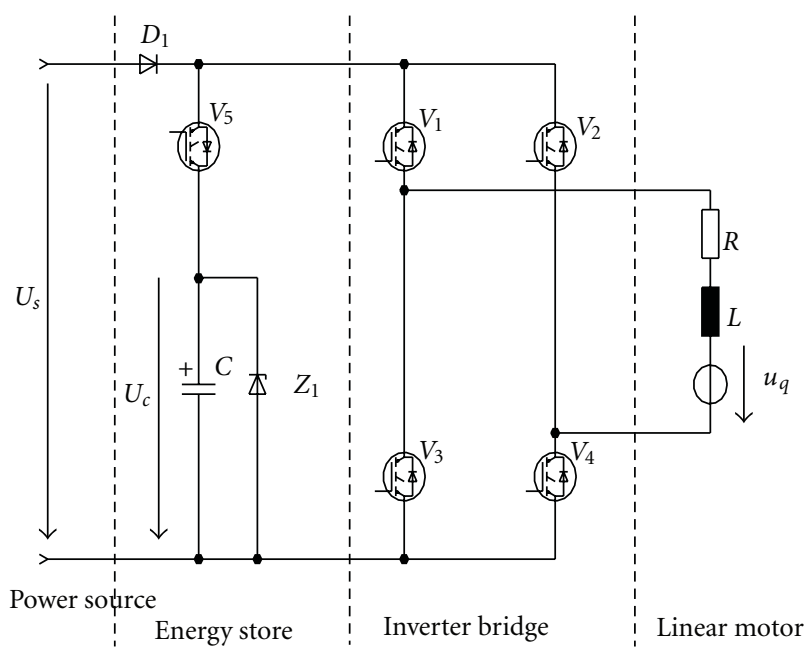

Figure 3: Multilevel inverter bridge structure.

words, there is always a (locally) unique solution for $i_{\text {coil }}(t)$ that depends on $D_{g} i_{\text {coil }}(t)$. Thus, using (13), the coil current can always be determined uniquely by the actuator position and its derivatives. Considering additional system equations, it can be easily seen that the flatness conditions defined in (9) are satisfied. Relationships (13) and (12) define the inverse system. Based on the flatness of the system, the linearizing trajectory of the model (3) and (2) is as follows:

$$
i_{d}(t)=\frac{m}{D_{g}\left(i_{d}(t)\right)}\left(\frac{k_{d}}{m} v_{d}(t)+\frac{k_{f}}{m} s_{d}(t)+\frac{\partial v_{d}(t)}{\partial t}\right),
$$

where $s_{d}(t)$ is the desired trajectory and $i_{d}(t)$ is the corresponding feed forward control current. As it was explained before, the flux does not depend on the position of the armature because the leakage flux is almost equal to zero. This means that the flux is a function of the current. Function $D_{g}\left(i_{\text {coil }}(t)\right)$ is never equal to zero, at least for our conceived structure, because of controllability. The actuator is conceived and designed in a way in order to guarantee the controllability at any point of its movement. For (1), the inverse system that determines the desired feedforward control input $u_{d}(t)$ is defined as follows:

$$
\begin{aligned}
u_{d}(t)= & L_{\text {coil }} \frac{\partial i_{d}(t)}{\partial t}+R_{\text {coil }} i_{d}(t) \\
& +D_{g}\left(i_{d}(t), s(t)\right) \frac{\partial s_{d}(t)}{\partial(t)} .
\end{aligned}
$$

Based on the feed forward control presented previously, the next step is to build a feedback control law that, in the presence of external disturbances and uncertainties in the parameters, takes the system around the desired trajectory.

\section{General MPC Problem Formulation}

Figure 3 shows the power electronic circuit feeding the permanent magnet linear actuator. The power supply is a 


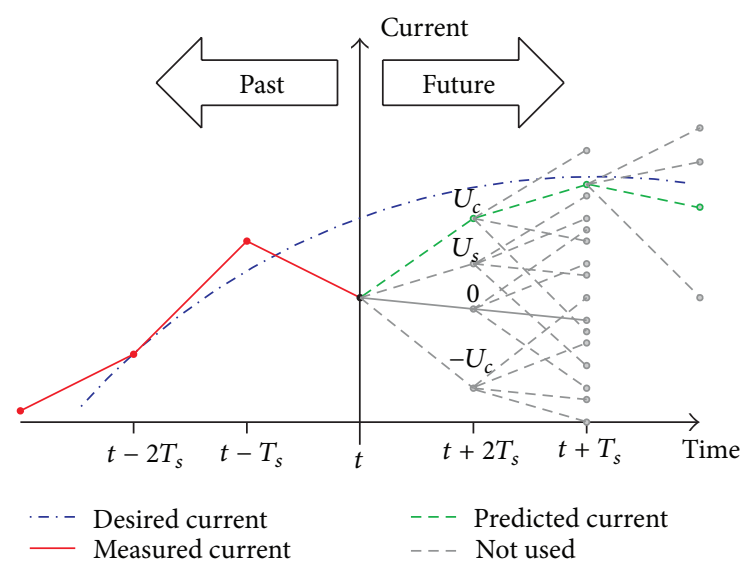

Figure 4: Principle of the complete applied MPC strategy.

constant voltage source $U_{S}$ (battery). However, to realize a current change as fast as possible to ensure the required dynamic, it is desirable to have a higher voltage applied to the actuator. Therefore, a capacitor $C$, charged with an initial voltage $U_{c}$ higher than the battery level, is used. To maintain the high voltage level of the capacitor during the valve operation, an energy storage block consisting of the capacitor $C$, the diode D5, and the IGBT switch V5 is used. Besides the current regulation, another task of the control strategy is to recharge the capacitor appropriately by utilizing the braking energy. On the right, the IGBT inverter bridge and the linear actuator are represented. Model predictive control has been a widely used control concept for over 15 years, especially in the process industry. Applications of MPC in the field of electrical drives are quite rare because of a high computational complexity. The central point of a model predictive controller is a process model, which is capable to predict future output signals based on future input signals and initial values. Using this process model, the future dynamic behavior of the real plant is predicted within a prediction horizon. These predicted output signals can be used to minimize an open loop performance criterion (e.g., the sum of squared control errors within the prediction horizon) and to calculate the input signals $u(k)$ for a control horizon. Outside the control horizon, the input remains constant. The calculated input signals feed the plant until a new measurement becomes available. This procedure is repeated with a receding prediction and control horizon. The receding horizon strategy makes a closed loop control law from the originally open loop minimization. The minimization step can easily include constraints, such as input, output, or state constraints, that may be taken into account already in the controller design. The principle of the predictive control design for the current control problem considered in this paper is depicted in Figure 4 with the desired current (dashed-point line) that results from the outer position control loop and the measured current (solid line). At the present time $t$, all possible currents for the future two time steps $t+t_{s} \cdots t+2 t_{s}$ are calculated. This calculation is performed based on a multimode model and assessed afterwards with the help of a defined cost function (details follow). The optimum switching configuration is also shown (bold-dashed line).

Figure 5 shows the whole proposed control structure. The presented technique can be interpreted in the following points.

(i) The positional MPC structure generates an optimal current trajectory with the desired optimal horizon through the electrical model.

(ii) The optimal current trajectory is used as a desired trajectory for the current MPC.

(iii) The current MPC makes it possible to calculate the switch control system structure.

Figure 5 shows the control system structure in which it is possible to recognize the desired current $i_{d}(t)$ which is used to linearize the system, the predicted reference current $i_{\text {opt }}(t)$, and current $i_{\text {coil }}(t)$.

\section{Solving a Linear Position MPC Optimization Problem}

To obtain the desired current trajectory, a position model predictive control is implemented. In this case, the sample time is relatively short, $40 \mu \mathrm{s}(25 \mathrm{kHz})$, to make the algorithm as fast as possible. Considering the model in (1), (2), and (3) in which $F_{0}(t)=0$ and an Euler discretization with $k=n t_{s}$, $n \in N$, where $t_{s}$ is the sampling time, the following system is obtained:

$$
\begin{array}{r}
i_{\text {coil }}(k+1) \\
=i_{\text {coil }}(k)+\frac{t_{s}}{L_{\text {coil }}}\left(-R_{\text {coil }} i_{\text {coil }}(k)+u_{\text {mpc }}(k)\right. \\
\left.+u_{d}(k)-u_{q}(k)\right) \\
s(k+1)=s(k)+t_{s} v(k) \\
v(k+1)=v(k)+t_{s}\left(\frac{D_{g}\left(i_{\text {coil }}(k)\right)}{m} i_{\text {coil }}(k)\right. \\
\left.+\frac{-k_{d} v(k)-k_{f} s(k)}{m}\right)
\end{array}
$$

where $u_{\mathrm{mpc}}(k)$ is the model predictive control input to be calculated and $u_{d}(k)$ and $u_{q}(k)$ are the discretized voltages of $u_{d}(t)$ and $u_{q}(t)$ already defined in (1), (2), and (3). If (13) is discretized, then

$$
\begin{aligned}
i_{d}(k)= & \frac{m}{D_{g}\left(i_{d}(k-1)\right)} \\
& \cdot\left(\frac{k_{d}}{m} v_{d}(k)+\frac{k_{f}}{m} s_{d}(k)+\frac{v_{d}(k+1)-v_{d}(k)}{t_{s}}\right) .
\end{aligned}
$$

Considering the Euler discretization of (14), which allows us to express the future value of an output as a function of the 


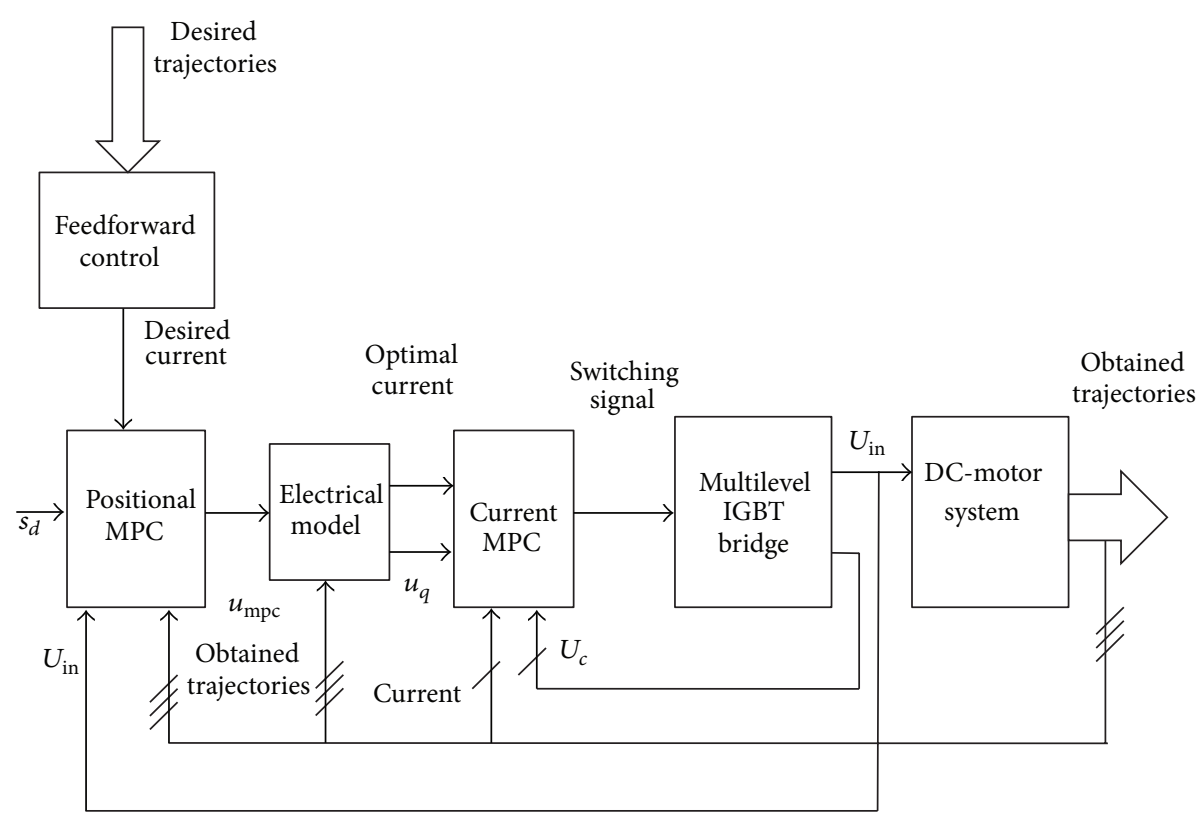

FIGURE 5: The whole control scheme.

pass inputs, which is the required form of the MPC approach, the following equation is obtained:

$$
\begin{aligned}
u_{d}(k)= & R_{\text {coil }} i_{d}(k)+L_{\text {coil }}\left(\frac{i_{d}(k+1)-i_{d}(k)}{t_{s}}\right) \\
& +u_{q}(k) .
\end{aligned}
$$

If (16) and (17) are inserted into the discretized equations (1), (2), and (3), then the following linear system is obtained:

$$
\begin{gathered}
i_{\text {coil }}(k+1)=i_{\text {coil }}(k)-i_{d}(k)+i_{d}(k+1) \\
-t_{s} \frac{R_{\text {coil }}}{L_{\text {coil }}}\left(i_{\text {coil }}(k)-i_{d}(k)-\frac{u_{\text {mpc }}(k)}{R_{\text {coil }}}\right) \\
s(k+1)=s(k)+t_{s} v(k) \\
v(k+1)=v(k)+t_{s}\left(\frac{k_{d} v_{d}(k)+k_{f} s_{d}(k)}{m}\right. \\
\left.-\frac{k_{d} v(k)+k_{f} s(k)}{m}\right) .
\end{gathered}
$$

If $\Delta u_{\mathrm{mpc}}(k)=u_{\mathrm{mpc}}(k)-u_{\mathrm{mpc}}(k-1)$ is assumed, the system described in (18) becomes

$$
\begin{gathered}
\mathbf{x}(k+1)=\mathbf{A}_{k} \mathbf{x}(k)+\mathbf{B}_{k}\left(\Delta u_{\mathrm{mpc}}(k)+u_{\mathrm{mpc}}(k-1)\right) \\
+\mathbf{E}_{k} \mathbf{d}(k) \\
\quad y(k)=\mathbf{H}_{k} \mathbf{x}(k)
\end{gathered}
$$

where matrix $\mathbf{H}_{k}=\left[\begin{array}{lll}0 & 1 & 0\end{array}\right]$ is the output matrix which determines the position, and the previous notation means

$$
\begin{aligned}
& \mathbf{A}_{k}=\left[\begin{array}{ccc}
\left(1-\frac{t_{s} R_{\text {coil }}}{L_{\text {coil }}}\right) & 0 & 0 \\
0 & 1 & t_{s} \\
0 & -\frac{t_{s} k_{f}}{m} & \left(1-\frac{t_{s} k_{d}}{m}\right)
\end{array}\right] \text {, } \\
& \mathbf{B}_{k}=\left[\begin{array}{c}
t_{s} \\
L_{\text {coil }} \\
0 \\
0
\end{array}\right], \\
& \mathbf{E}_{k}=\left[\begin{array}{cccl}
1 & \left(\frac{t_{s} R_{\text {coil }}}{L_{\text {coil }}}-1\right) & 0 & 0 \\
0 & 0 & 0 & 0 \\
0 & 0 & \frac{t_{s} k_{f}}{m} & \frac{t_{s} k_{d}}{m}
\end{array}\right] \text {, } \\
& \mathbf{d}(k)=\left[\begin{array}{c}
i_{d}(k+1) \\
i_{d}(k) \\
s_{d}(k) \\
v_{d}(k)
\end{array}\right] .
\end{aligned}
$$

In the considered representation, vector $\mathbf{d}(k)$ is the known input. In the model approach, just two samples are considered:

$$
\begin{aligned}
\widehat{s}(k+1)= & \mathbf{H}_{k} \mathbf{A}_{k} \mathbf{x}(k) \\
& +\mathbf{H}_{k} \mathbf{B}_{k} \Delta u_{\mathrm{mpc}}(k)+\mathbf{H}_{k} \mathbf{B}_{k} \Delta u_{\mathrm{mpc}}(k-1) \\
& +\mathbf{H}_{k} \mathbf{E}_{k} \mathbf{d}(k),
\end{aligned}
$$




$$
\begin{aligned}
\widehat{s}(k+2)= & \mathbf{H}_{k} \mathbf{A}_{k}^{2} \mathbf{x}(k) \\
& +\mathbf{H}_{k} \mathbf{A}_{k} \mathbf{B}_{k} \Delta u_{\mathrm{mpc}}(k) \\
& +\mathbf{H}_{k} \mathbf{A}_{k} \mathbf{B}_{k} \Delta u_{\mathrm{mpc}}(k-1) \\
& +\mathbf{H}_{k} \mathbf{B}_{k} \Delta u_{\mathrm{mpc}}(k+1) \\
& +\mathbf{H}_{k} \mathbf{B}_{k} \Delta u_{\mathrm{mpc}}(k)+\mathbf{H}_{k} \mathbf{A}_{k} \mathbf{E}_{k} \mathbf{d}(k) \\
& +\mathbf{H}_{k} \mathbf{E}_{k} \mathbf{d}(k) .
\end{aligned}
$$

If the following performance criterion is assumed,

$$
\begin{aligned}
J= & \frac{1}{2} \sum_{j=1}^{N}\left(s_{d}(k+j)-\widehat{s}(k+j)\right)^{T} \\
& \cdot \mathbf{Q}_{p}\left(s_{d}(k+j)-\widehat{s}(k+j)\right) \\
& +\sum_{j=1}^{N}\left(\Delta u_{\mathrm{mpc}}(k+j)\right)^{T} \\
& \cdot \mathbf{R}_{p} \Delta u_{\mathrm{mpc}}(k+j),
\end{aligned}
$$

where $s_{d}(k+j), j=1,2, \ldots, N$, is the position reference trajectory, $N$ the prediction horizon, and $\mathbf{Q}_{p}$ and $\mathbf{R}_{p}$ are nonnegative definite matrices, then the solution minimizing performance index (22) may be then obtained by solving

$$
\frac{\partial J}{\partial \Delta u_{\mathrm{mpc}}}=0 .
$$

If only two steps for the prediction horizon are considered, then

$$
\begin{gathered}
\mathbf{G}_{p}=\left[\begin{array}{c}
\mathbf{H}_{k} \mathbf{A}_{k} \\
\mathbf{H}_{k} \mathbf{A}_{k}^{2}
\end{array}\right], \quad \mathbf{F}_{1 p}=\left[\begin{array}{cc}
\mathbf{H}_{k} \mathbf{B}_{k} & 0 \\
\mathbf{H}_{k} \mathbf{A}_{k} \mathbf{B}_{k}+\mathbf{H}_{k} \mathbf{B}_{k} & \mathbf{H}_{k} \mathbf{B}_{k}
\end{array}\right], \\
\mathbf{F}_{2 p}=\left[\begin{array}{c}
\mathbf{H}_{k} \mathbf{B}_{k} \\
\mathbf{H}_{k} \mathbf{A}_{k} \mathbf{B}_{k}+\mathbf{H}_{k} \mathbf{B}_{k}
\end{array}\right], \\
\mathbf{F}_{3 p}=\left[\begin{array}{cc}
\mathbf{H}_{k} \mathbf{E}_{k} & 0 \\
\mathbf{H}_{k} \mathbf{A}_{k} \mathbf{E}_{k}+\mathbf{H}_{k} \mathbf{E}_{k} & \mathbf{H}_{k} \mathbf{E}_{k}
\end{array}\right] .
\end{gathered}
$$

A direct computation may be obtained explicitly as

$$
\begin{aligned}
\Delta u_{\mathrm{mpc}}(k)= & \left(\mathbf{F}_{1 p}^{T} \mathbf{Q}_{p} \mathbf{F}_{1 p}+\mathbf{R}_{p}\right)^{-1} \\
& \cdot\left(\mathbf { F } _ { 1 p } ^ { T } \mathbf { Q } _ { p } \left(\mathbf{Y}_{d_{p}}(k)-\mathbf{G}_{p} x(k)\right.\right. \\
& \left.\left.\quad-\mathbf{F}_{2 p} u_{\mathrm{mpc}}(k-1)-\mathbf{F}_{3 p} \mathbf{d}(k)\right)\right),
\end{aligned}
$$

where $\mathbf{Y}_{d_{p}}(k)$ is the desired output column vector. Once the predicted optimized voltage is obtained, then it is possible to obtain the predicted optimized current as the reference current for the current MPC based on the model of the system.
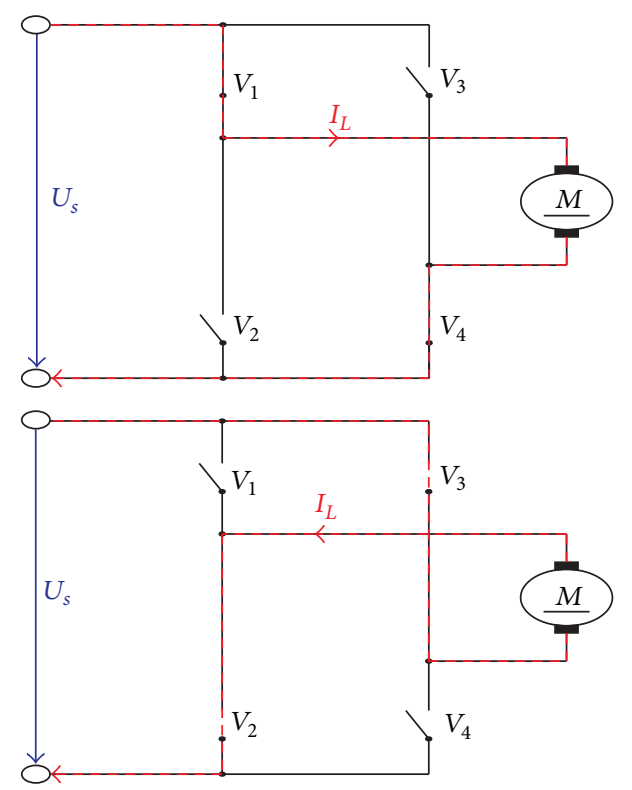

FIGURE 6: Working phases one and two (fed by $U_{s}$ ).
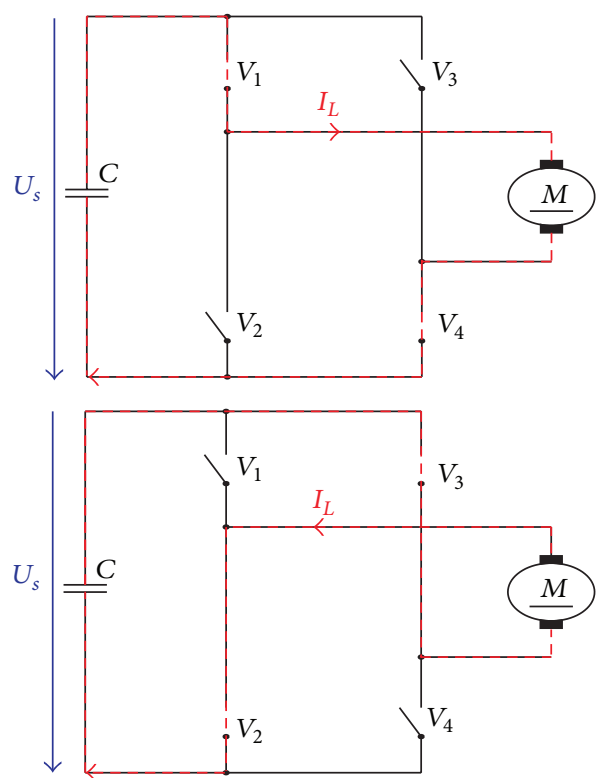

FIgURE 7: Working phases three and four (fed by $U_{C}$ ).

Remark 1. It should be noted that, because of the linearization around a trajectory, the model depends on the value of the trajectory, which is formalized in vector $\mathbf{d}(k)$.

\section{Inverter and Motor Electrical Model in Current MPC Structure}

Given a desired current reference, the goal is to control the real actuator current following this signal by a switched voltage. Direct control of the switching states has some 

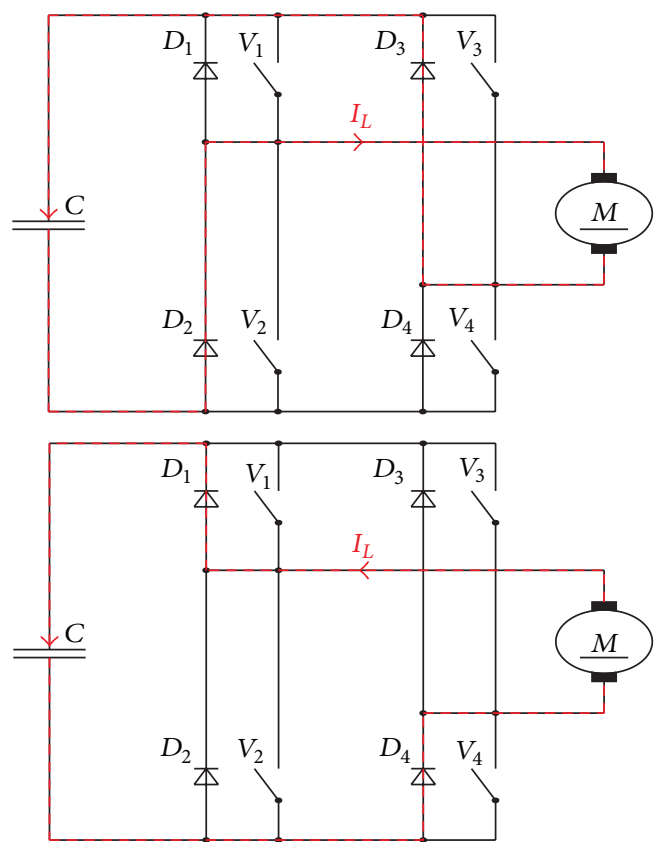

Figure 8: Phase five: capacitor charging phase.
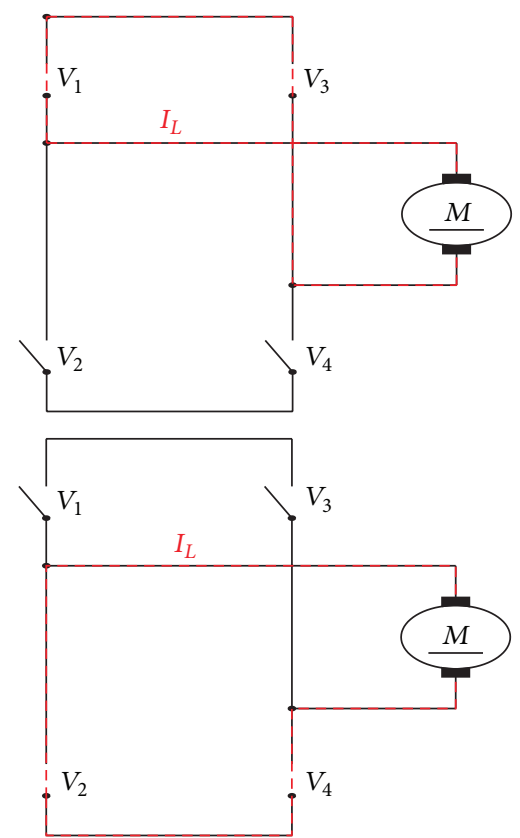

FIGURE 9: Working phase six (freewheeling).

advantages over the conventional pulse-width modulation method: the reachable dynamic is higher, and no pulsepattern generation is needed. However, a proper switching strategy is necessary, and chattering phenomena can occur due to measurement noise. To provide a good reference, the

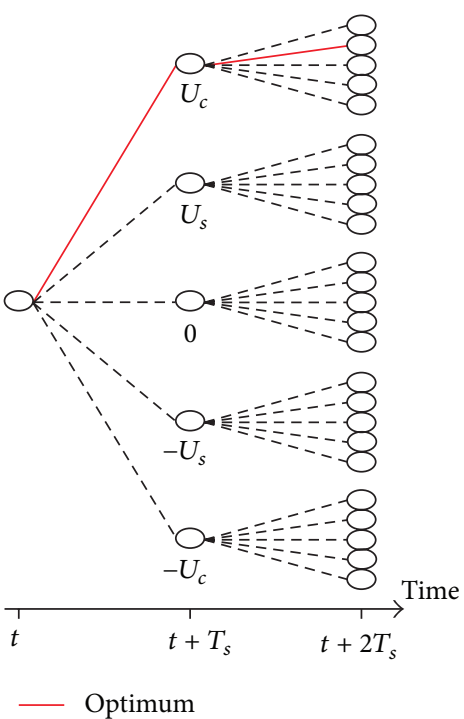

FIgURE 10: Three of the combinations in two-step prediction.

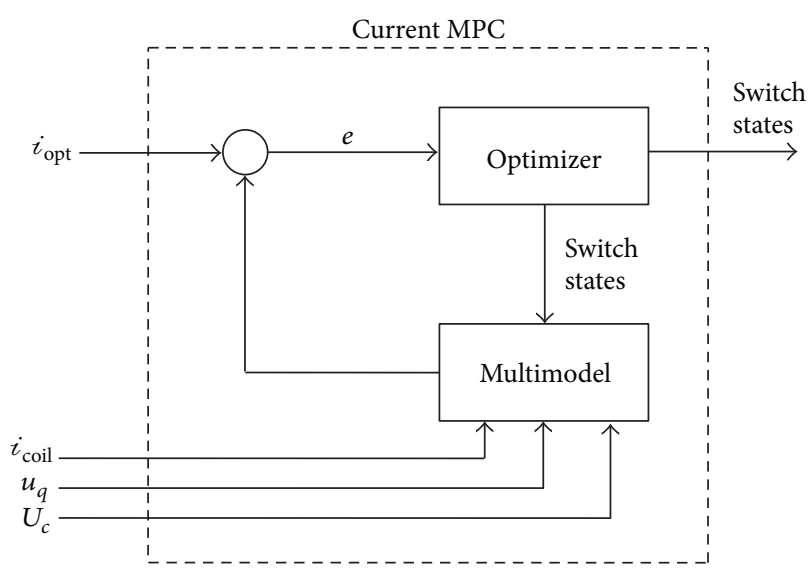

FIGURE 11: Scheme of the multimodel predictive control.

following control problem is stated: given the system depicted in Figure 3 and the following linear system for the actuator:

$$
\frac{\partial i_{\text {coil }}(t)}{\partial t}=-\frac{R_{\text {coil }}}{L_{\text {coil }}} i_{\text {coil }}+\frac{\mathcal{U}_{\text {in }}-u_{q}(k)}{L_{\text {coil }}},
$$

where $\mathcal{U}_{\text {in }} \in\left[u_{1}, u_{2}, u_{3}, u_{4}, u_{5}\right]=\mathscr{I}$ is the available set of input voltages applied to the actuator and $u_{q}(k)$ is the induced back voltage of the linear actuator. Find a sequence $\mathcal{U}^{*}$ of $p$ elements $u \in \mathscr{I}$ such that

$$
\begin{array}{r}
J=\min _{U_{\text {in }}} \frac{1}{2} \sum_{j=1}^{N_{p}}\left(\hat{i}_{\text {coil }}(k+j)-i_{\text {opt }}(k+j)\right) \mathbf{Q}_{i} \\
\cdot\left(\hat{i}_{\text {coil }}(k+j)-i_{\text {opt }}(k+j)\right) \\
+\sum_{k=1}^{N_{p}} \frac{1}{2}\left(\Delta U_{c}(k+j)\right) \mathbf{R}_{i} \cdot\left(\Delta U_{c}(k+j)\right),
\end{array}
$$




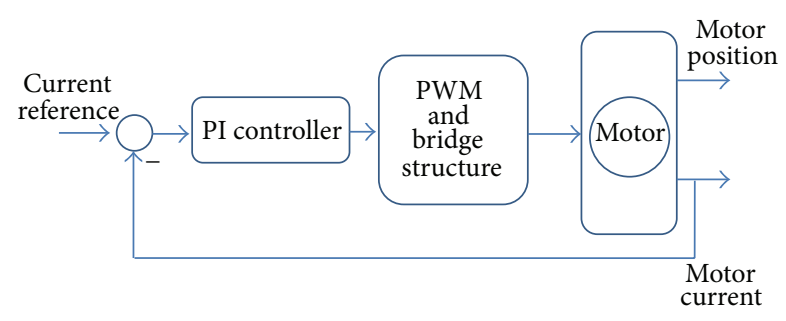

(a)

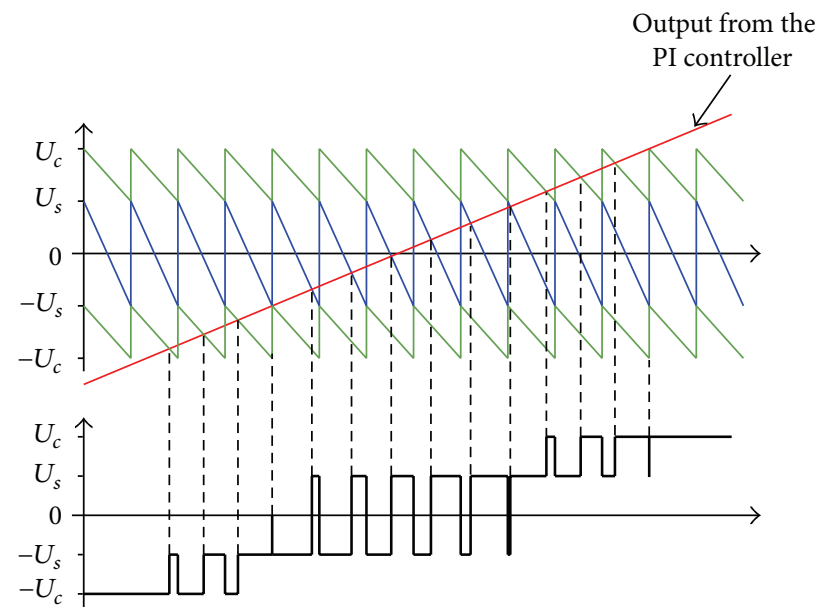

(b)

FIgure 12: (a) Control scheme using PI controller in the loop. (b) PWM generation.

where $\hat{i}_{\text {coil }}(k)$ is the predicted current, $i_{\text {opt }}(k)$ is an optimized current which is assumed to be a reference current (this current is calculated by the positional MPC structure), and $N_{p}$ is the prediction horizon (equal to the control horizon in our case). $\mathbf{Q}_{i}$ is the selection matrix of the weights of the current error, and $\mathbf{R}_{i}$ is a selection matrix of the weights of the input voltage.

It is worthwhile to remark that the matrices $\mathbf{Q}_{i}$ provide adaptive weights depending on the length of the prediction horizon. The formulation in (26) and (27) is a well-known system with switching command variables. In our case, if a short prediction horizon (2-4 samples) is considered, the induced back voltage $u_{q}$ could, in this interval, be treated as constant. Observing Figure 3, five working phases are identified. These working phases are summarized as follows.

(i) Working phase one: IGBT 2 and IGBT 3 on; IGBT 1 and IGBT 4 off; IGBT 5 off (Figure 6).

(ii) Working phase two: IGBT 2 and IGBT 3 off; IGBT 1 and IGBT 4 on; IGBT 5 off (Figure 6).

(iii) Working phase three: IGBT 1 and IGBT 4 on; IGBT 2 and IGBT 3 off; IGBT 5 on (Figure 7).

(iv) Working phase four: IGBT 1 and IGBT 4 off; IGBT 2 and IGBT 3 on; IGBT 5 on (Figure 7).

(v) Working phase five: IGBT 2 and IGBT 3 off; IGBT 1 and IGBT 4 off; IGBT 5 on (Figure 8).
MPC Representation. In general, dependence on the switching configuration the discrete-time dynamic model of the considered system can be formulated in one of the following two ways:

$$
i_{\text {coil }}(k+1)=\mathbf{A}_{1} i_{\text {coil }}(k)+\mathbf{B}_{1}\left(U_{s}-u_{q}(k)\right),
$$

where the pair $\left(\mathbf{A}_{1}, \mathbf{B}_{1}\right)$ represents the first order "R-L" system depicted in Figure 6 or by defining

$$
\mathbf{x}(k)=\left[\begin{array}{l}
i_{\text {coil }}(k) \\
U_{c}(k)
\end{array}\right] .
$$

The dynamic of phases three and four is

$$
\begin{gathered}
\mathbf{x}(k+1)=\mathbf{A}_{2} x(k)+\mathbf{B}_{2}\left(-u_{q}(k)\right), \\
y(k)=\mathbf{C}_{2} \mathbf{x}(k)=i_{\text {coil }}(k),
\end{gathered}
$$

where the term $\left(A_{2}, B_{2}, C_{2}\right)$ represents the second order " $\mathrm{R}$ L-C" system depicted in Figure 8.

(i) During the commutation from phases "one and two" to phases "three and four," the predicted current with a prediction horizon equal to 2 is

$$
\begin{aligned}
i_{\text {coil }}(k+2)= & C_{2} A_{2}\left[\begin{array}{c}
A_{1} i_{\text {coil }}(k)+B_{1}\left(U_{s}-u_{q}(k)\right) \\
U_{c}(k)
\end{array}\right] \\
& +C_{2} B_{2}\left(-u_{q}(k)\right)
\end{aligned}
$$

where $U_{c}(k)$ is the measured capacitor voltage, $i_{\text {coil }}(k)$ is the measured coil current, and $u_{q}(k)$ is induced voltage (back voltage), which can be estimated by a state observer.

(ii) During commutation from phases "three and four" to phases "one and two," the predicted current with a prediction horizon equal to 2 samples is

$$
\begin{aligned}
i_{\text {coil }}(k+2)= & A_{1} C_{2} A_{2}\left[\begin{array}{c}
i_{\text {coil }}(k) \\
U_{c}(k)
\end{array}\right]+C_{2} B_{2}\left(-u_{q}(k)\right) \\
& +C_{1} B_{1}\left(U_{s}-u_{q}(k)\right) .
\end{aligned}
$$

(iii) Phase five is the phase in which the capacitor is charged, and it could be represented as

$$
\begin{aligned}
i_{\text {coil }}(k+2)= & -C_{2} A_{2}\left[\begin{array}{c}
A_{1} i_{\text {coil }}(k)+B_{1}\left(U_{s}-u_{q}(k)\right) \\
U_{c}(k)
\end{array}\right] \\
& -C_{2} B_{2}\left(-u_{q}(k)\right) .
\end{aligned}
$$

The voltage of the capacitor, $U_{c}(k)$, is measurable, and the voltage $u_{q}(k)$ is assumed to be constant in the prediction period. 


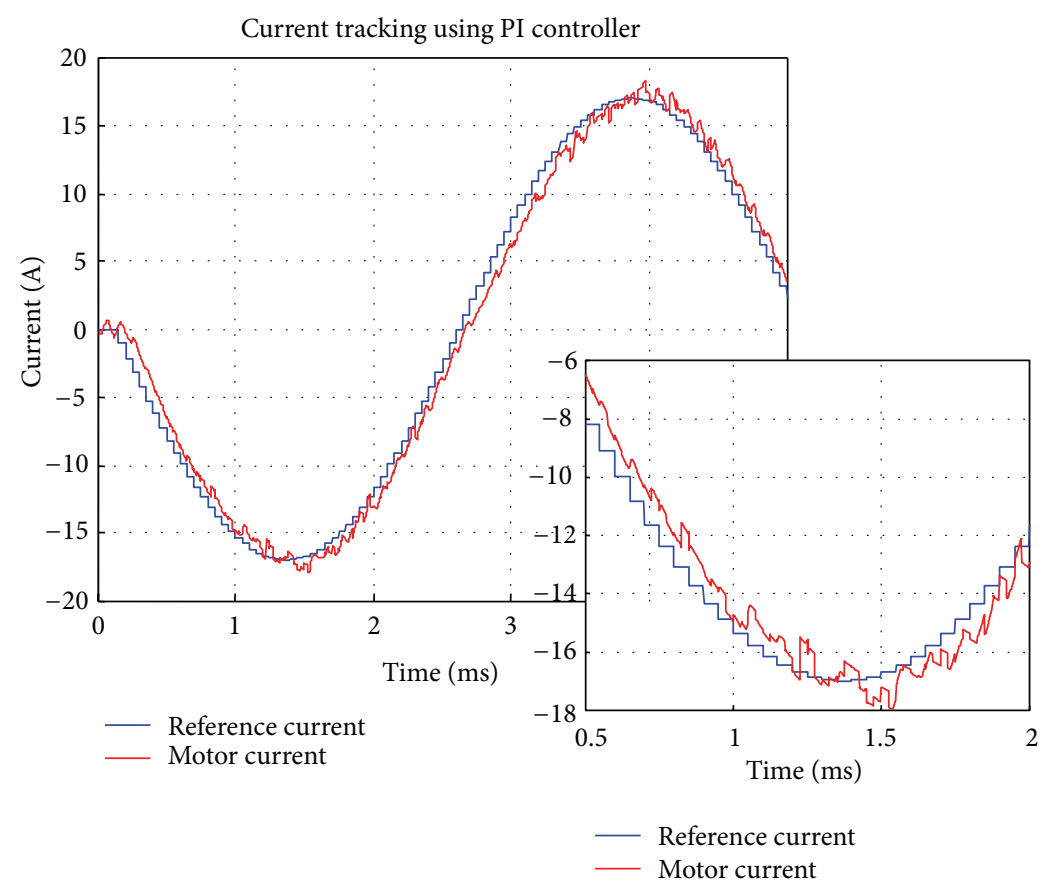

FIGURE 13: Current tracking obtained with the control scheme of Figure 12.

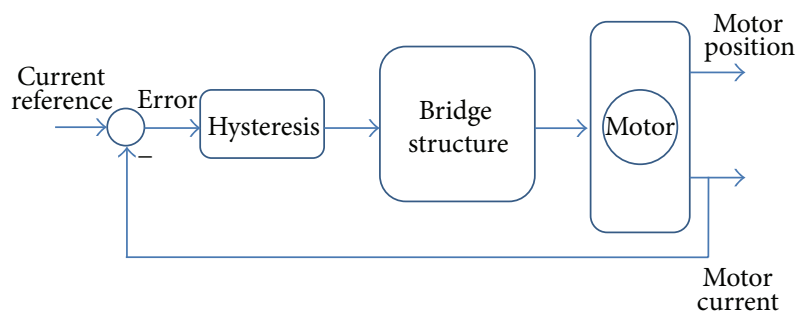

Figure 14: Control scheme using hysteresis controller in the loop.

6.1. Optimization and Current Control Technique. Generally, MPCs suffer from high computational complexity in online applications. In the presented case, there are theoretically 32 possible configurations of the IBGT switching states, but only 6 of them are used in practice; most of them cannot be used because they generate short circuits, and others are practically redundant. If a global optimum is wanted in a "one-step" prediction horizon, then there are at most 5 possible voltage combinations. In general, for $N$-step prediction, there are $5^{N}$ possible combinations. This problem is known as an NPcomplete problem (the solution time grows exponentially with the problem size). Thus, in a general solution of the optimization problem, all $5^{N}$ possible states must be taken into account, which means that the calculation time is expected to be relatively high. However, for short prediction horizons, using this method to determine the controller is still reasonable. In Figure 10, this situation is depicted. Three logical inputs $u_{l 1}(t), u_{l 2}(t), u_{l 3}(t) \in\{0,1\}$ which identify the configurations are defined. Besides the general optimization solution described previously, a different optimization procedure, which is actually the well-known branch and bound method, was used. In this case $0-1$ combinations through a binary tree are explored. The feasible region is partitioned in subdomains systematically, and valid upper and lower bounds are generated at different levels of the binary tree. The main advantage of the branch and bound method is that it can be interrupted at any intermediate step to obtain a suboptimal solution, although, in this case, the tracking performance deteriorates. To build a procedure for finding a local optimum, the following definition is introduced.

Definition 2. Given a voltage and inverter bridge configuration at time $k$ that corresponds to the minimum of the function defined in (27) and its logical code, a "near permutation" at time $k+1$ is defined as "the combination code," which identifies the two nearest possible voltages to the minimum at time $k$.

If the "near permutation" at time $k$ is considered, then the following procedure is proposed.

Step 1. Let $\mathbf{u}_{l}^{\star}$ be an initial optimum of logic inputs that is found by a total search.

Step 2. Consider $\mathbf{u}_{l}^{\star}$ and its "near permutations" in an $N_{p}$ prediction horizon branch phase.

Step 3. Check the cost function defined in (27) around $\mathbf{u}_{l}^{\star}$ to bound the branch.

Step 4. Find the minimum in the branch. 


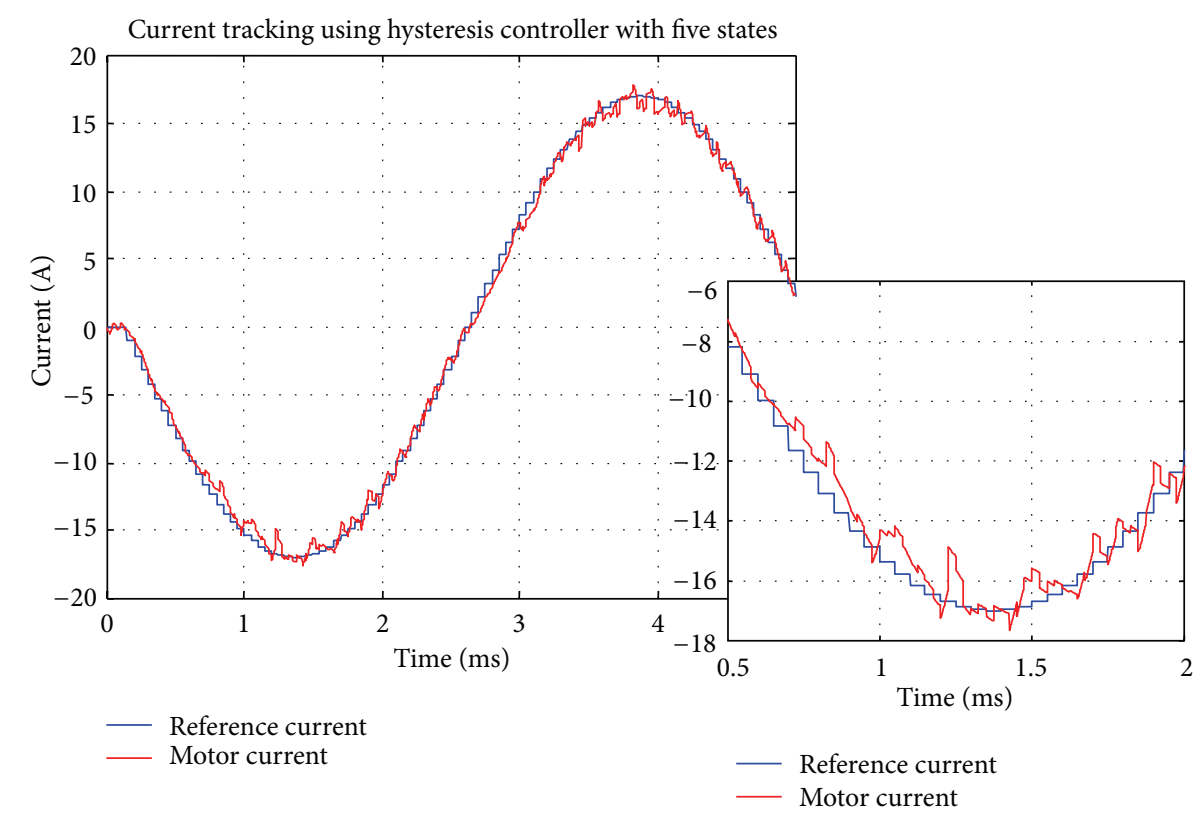

FIGURE 15: Current tracking obtained with the control scheme of Figure 14.

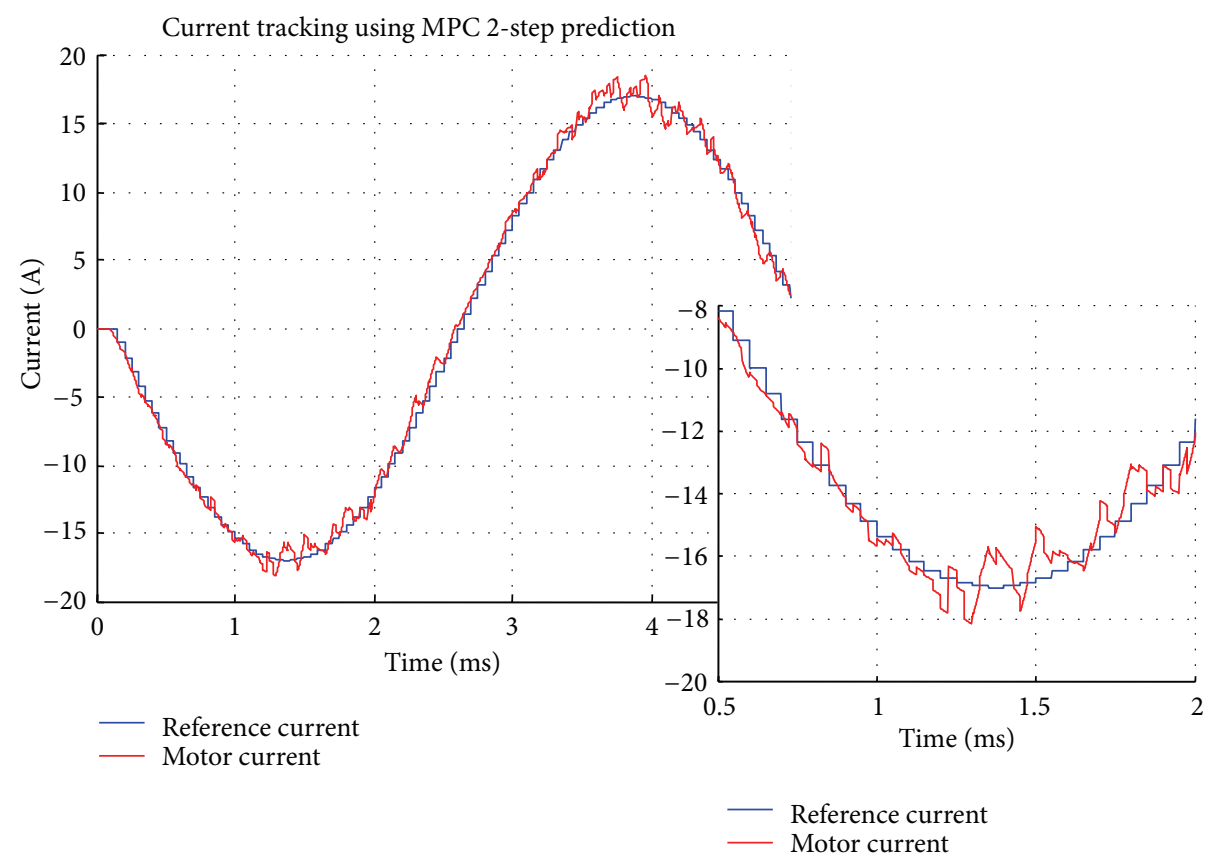

FIGURE 16: Current tracking obtained using an MPC (2-step prediction) with the control scheme of Figure 11.

Step 5. Branch around the new minimum candidate and check the cost function (27) to bound the branch.

Step 6. Go to Step 4 until the specified time out.

The procedure described previously is suitable for current reference values that do not contain steps or very fast changes. In these cases, it is possible to assume that the optimum in
(27) changes slowly and that the computational advantages are known. At the first step control horizon, all the switching possibilities are considered to manage abrupt changes that may arise. The following step horizons only consider the "adjacent switch possibility." In general, independently of the optimal search technique, Figure 11 shows the structure of the proposed controller. As shown previously [33], this type of approach could also be useful in nonlinear control 


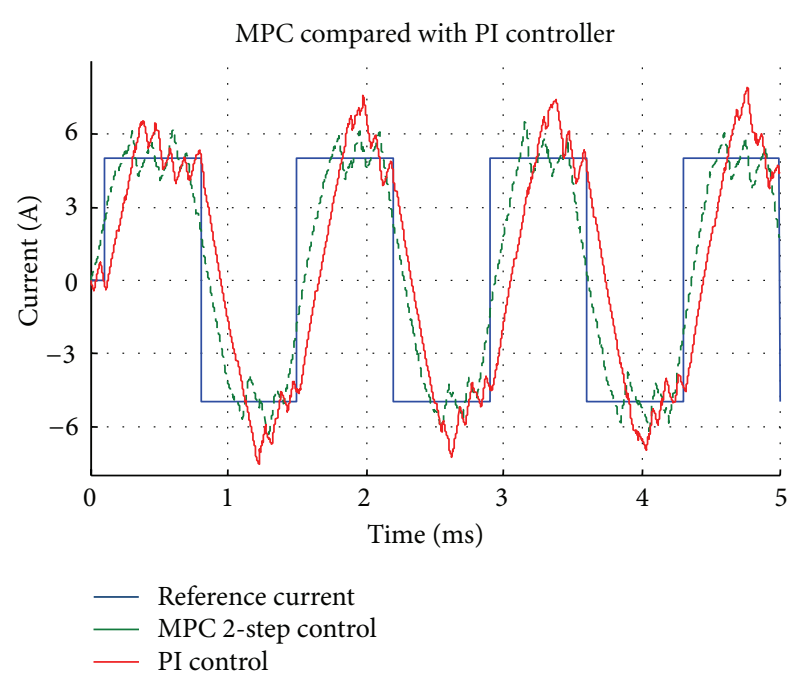

FIGURE 17: Step test: current tracking obtained using MPC (2-step prediction) and PI controller.

systems. In fact, as proposed elsewhere [34], it is possible to describe a nonlinear system with this technique, which normally works around known working points, with a set of corresponding linear systems. In our presented case the set has $5^{N}$ models. As already discussed, current control is particularly important for positioning a mechatronic system. It is also possible to build an MPC outer loop, as depicted in Figure 5. In other words, the desired current is calculated to minimize the quadratic error between the desired position and the predicted position for the current control loop.

\section{Robust Stability Considerations and Simulation Results}

In the presented case the performances are tested through numerical simulations. The numerical simulations are performed considering an extension of a sufficient condition stated in [35, Lemma 3.1]. If the systems defined previously are characterized by the following dynamic matrices, $\mathbf{A}_{k}, \mathbf{A}_{1}$, and $\mathbf{A}_{2}$ are stable, and if for all matrices $\mathbf{Q}_{p}$ and $\mathbf{Q}_{i}$ as in (22) and (27) there exist matrices $\mathbf{P}_{p}, \mathbf{P}_{1 i}$, and $\mathbf{P}_{2 i}$ such that

$$
\begin{aligned}
& \mathbf{A}_{k}^{T} \mathbf{P}_{p} \mathbf{A}_{k}-\mathbf{P}_{p}=-\mathbf{Q}_{p}, \\
& \mathbf{A}_{1}^{T} \mathbf{P}_{1 i} \mathbf{A}_{1}-\mathbf{P}_{1 i}=-\mathbf{Q}_{i}, \\
& \mathbf{A}_{2}^{T} \mathbf{P}_{2 i} \mathbf{A}_{2}-\mathbf{P}_{2 i}=-\mathbf{Q}_{i},
\end{aligned}
$$

then one has the perturbed systems:

$$
\begin{aligned}
& \mathbf{x}(k+1)=\mathbf{A}_{k} \mathbf{x}(k)+\mathbf{m}_{p} \mathbf{A}_{k} \mathbf{x}(k), \\
& \mathbf{x}(k+1)=\mathbf{A}_{1} \mathbf{x}(k)+\mathbf{m}_{1} \mathbf{A}_{1} \mathbf{x}(k), \\
& \mathbf{x}(k+1)=\mathbf{A}_{2} \mathbf{x}(k)+\mathbf{m}_{2} \mathbf{A}_{2} \mathbf{x}(k),
\end{aligned}
$$

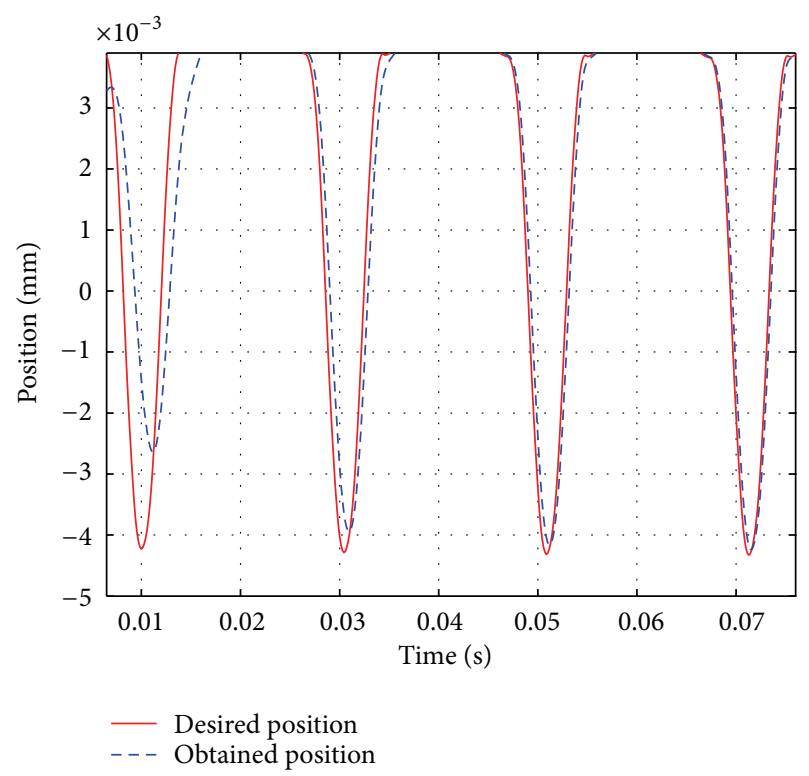

(a)

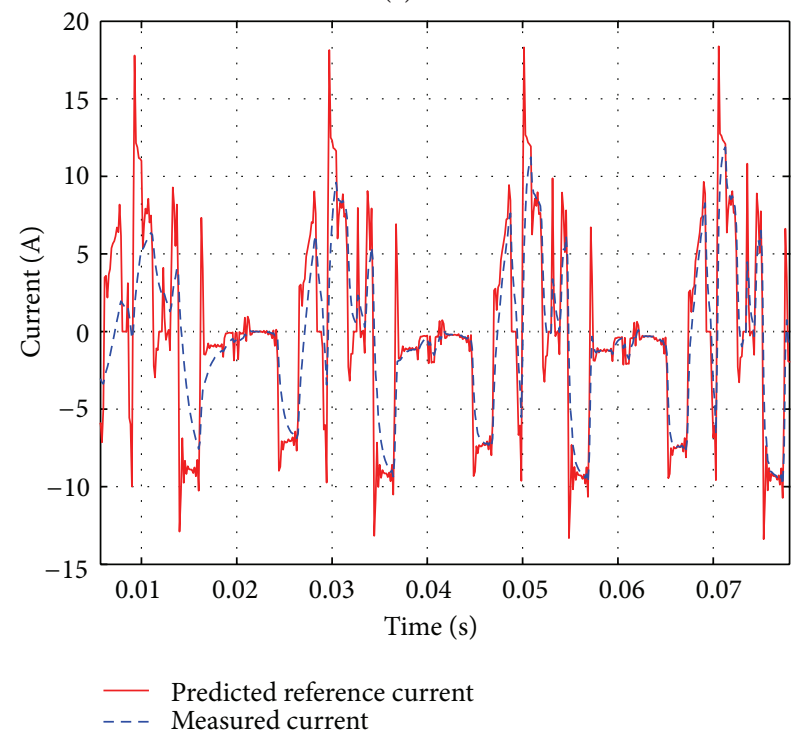

(b)

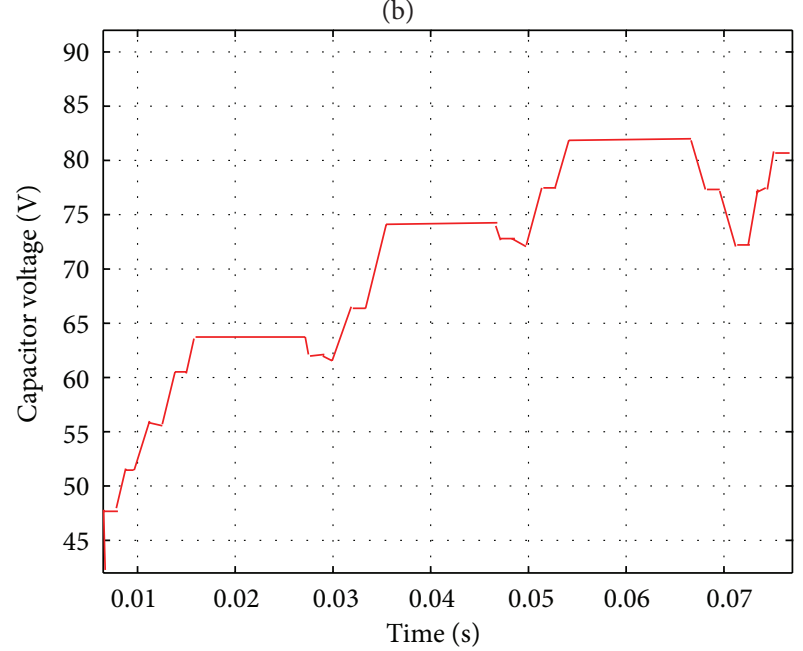

(c)

FIGURE 18: From the top: three cycles for position, current tracking, and capacity charging using MPC. 
where $\mathbf{m}_{p}, \mathbf{m}_{1}$, and $\mathbf{m}_{2}$ are matrices with appropriate dimensions and are open loop stable if

$$
\begin{aligned}
& \left\|\mathbf{m}_{p} \mathbf{A}_{k}\right\| \leq \min \left\{\frac{\lambda_{\text {min }}\left(\mathbf{Q}_{p}\right)}{2\left\|\mathbf{A}_{k}^{T} \mathbf{P}_{p}\right\|+\left\|\mathbf{P}_{p}\right\|}, 1\right\}, \\
& \left\|\mathbf{m}_{1} \mathbf{A}_{1}\right\| \leq \min \left\{\frac{\lambda_{\text {min }}\left(\mathbf{Q}_{i}\right)}{2\left\|\mathbf{A}_{1}^{T} \mathbf{P}_{1}\right\|+\left\|\mathbf{P}_{1}\right\|}, 1\right\}, \\
& \left\|\mathbf{m}_{1} \mathbf{A}_{2}\right\| \leq \min \left\{\frac{\lambda_{\text {min }}\left(\mathbf{Q}_{i}\right)}{2\left\|\mathbf{A}_{2}^{T} \mathbf{P}_{2}\right\|+\left\|\mathbf{P}_{2}\right\|}, 1\right\} .
\end{aligned}
$$

To stabilize the open loop structure robustly, $\mathbf{Q}_{(\cdot)}=\mathbf{I}$. As described in [35, Theorem 3.1] states that it is possible to stabilize the positional MPC in a closed loop. In fact, the theorem mentioned previously states a sufficient condition:

$$
\left\|\left(\mathbf{F}_{1 p}^{T} \mathbf{Q}_{p} \mathbf{F}_{1 p}+\mathbf{R}_{p}\right)^{-1}\left(\mathbf{F}_{1 p}^{T} \mathbf{Q}_{p}\right)\right\|<\min \left\{\frac{1}{2\left\|\mathbf{A}^{T} \mathbf{P}_{p}+\mathbf{P}_{p}\right\|}, 1\right\} .
$$

In our case, the control structure is a cascade of controllers. No stability conditions are given in the literature. The heuristic procedure to obtain the stability of the whole system, which was adopted in this paper, consists of finding the gain of the positional MPC according to relation (37) and testing the stability of the whole loop control structure. If the loop is not stable, then the value of matrix $\mathbf{Q}_{i}$ is reduced, and the method is repeated. This trial-and-error technique causes the system to achieve stability. It is always possible to consider a number of models as in [34] such that the uncertainties of the system respect the sufficient condition stated in [35, Lemma 3.1]. To justify the presented approach, the following comparison results are reported that track the current control. These results provided some essential information regarding the presented research direction. To compare the performance of a possible control strategy, the second MPC was considered. The results shown in Figures 13,15 , and 16 are obtained through the control structure presented in Figures 11, 12, and 14, using a current sinusoidal test signal. In Table 1, the results are summarized. From these results, a majority of the approximations of the MPC are superior if a minimum number of models are considered. This set of models was used to determine the best value of the $u_{q}(k)$ voltage at the moving working point as proposed in [34]. A sinusoidal test function was chosen based on the fundamental harmonic of the current in a real working system. Moreover, to complete the comparison, a step test, the results of which are summarized in Figure 17, was done. Also, in this case, the superiority of the MPC seems to be evident, see Table 2. With both the hysteresis controller and the PI controller, it is not possible to recharge the capacitor, at least not with our proposed bridge structure. After determining the superiority of the MPC for our task [36], an MPC that follows a given current profile was presented, and in [37], a similar control strategy was shown but with a bridge with the capacitor recharging structure and a new control law. In [37], no trajectory tracking was analyzed. Nevertheless, PI
TABLE 1: Comparison of the results in the sinusoidal test current.

\begin{tabular}{lccc}
\hline$H$ & MPC & Hysteresis regulator & PI regulator \\
\hline $\begin{array}{l}\text { Energy } \\
\text { error }\end{array}$ & $0.23 \%(0.39 \%)$ & $0.35 \%$ & $1.25 \%$ \\
$\left(\int e^{2} d t\right)$ & & & \\
$\begin{array}{l}\text { Calculation } \\
\text { complexity }\end{array}$ & $30(5)$ models & - & - \\
\hline
\end{tabular}

TABLE 2: Comparison of the results in the step test current.

\begin{tabular}{lccc}
\hline$H$ & MPC & Hysteresis regulator & PI regulator \\
\hline $\begin{array}{l}\text { Energy } \\
\text { error }\end{array}$ & $24 \%(42 \%)$ & $40 \%$ & $45 \%$ \\
$\left(\int e^{2} d t\right)$ & & & \\
$\begin{array}{l}\text { Calculation } \\
\text { complexity }\end{array}$ & $30(5)$ models & - & - \\
\hline
\end{tabular}

controllers and hysteresis controller are very often used in these kinds of applications. Even though we must renounce to recharge the capacitor, PI and hysteresis controllers are very often used because of their simplicity to be realized. Based on the real pressure acting in a valve actuator, motion with an exponential disturbance with an initial value equal to $400 \mathrm{~N}$ is simulated, even though in the control law $F_{0}(t)=0$. Special attention was paid to the applicability of the control system. In fact, the sample time was $40 \mu \mathrm{s}$. In this time, just a limited number of arithmetical operations can be performed, and for this reason, the simulation was performed with $N=2$ (prediction horizon).

7.1. Capacitor Recharging. Along with the tracking task, another interesting aspect is the following: a self-recharging voltage capacitor control. A capacitor can be charged in working phase 5 , where the motor inductance either allows the charging current or the mechanical braking energy can be fed back. Thus, appropriately partitioning the working phases can make both tracking and recharging possible. The balance between these two tasks is achieved by the cost function defined in (27). Depending on the motion cycle dynamic, the weights $\mathbf{Q}_{j}$ and $\mathbf{R}_{j}$ were set to maintain the level of the voltage capacitor within an acceptable tolerance. Thus, in particular $\Delta U_{c}(k)=\left(U_{c}(k)-U_{c d}^{*}\right)$, where $U_{c}(k)$ is the measured voltage of the capacitor and $U_{c d}^{*}$ is its desired level, which should be kept within a tolerance band. The capacitor voltage is used to enable high dynamic changes in the actuator current, which in turn cause large variations in the capacitor voltage. Thus, the system could not be operated continuously if the capacitor control was not included in the optimization procedure. Furthermore, efficiency was improved by properly utilizing the mechanical braking energy. Simulation results were achieved using real data, and they show promising results. In this phase, some different control strategies were tested using real data from the already-built valve. The results encourage proceeding in the prototyping phase, in which the rest of the structure, which basically consists of a DSP, must have a power bridge according to the simulated data. 
Some interesting aspects are worth identifying. The lower part of Figure 18 shows how the self-charging phase can start during the following phase. In this case, an initial error occurs as long as the capacitor does not achieve the full voltage. In the presented simulated case, the initial voltage value in the capacitor is $48 \mathrm{~V}$. It is possible to start from $0 \mathrm{~V}$; in this case the charging phase lasts 6 cycles more, if the same weighting matrices are considered in the cost function. To achieve a higher charging velocity it is necessary to increase the matrix $\mathbf{R}_{j}$ in the index (27). Finally, it is interesting to note that through MPC, it is possible to obtain a self-balanced switch of the IBGT. In fact Figure 9 shows two possible freewheeling circuits. It is acceptable to balance the switching phase on these two circuits to obtain a balance frequency. A compromise between good tracking and stability of the supply voltage is achieved. In particular, good capacitor voltage stability provides the necessary condition for good follow-up results; it is always necessary to identify the tradeoff between capacitor voltage stability and followup.

\section{Conclusions and Outlook}

The paper implements a multilevel inverter control system by integrating flatness and two cascaded MPCs. The first MPC generates an optimal desired current by minimizing the position error. The second MPC considers this optimal desired current as a reference signal to find an optimal switching law for the proposed multilevel inverter. The current MPC considers energy storage optimization using a capacitor in the proposed inverters. Finally, simulations using real data are shown.

\section{Acknowledgment}

The author thanks the Institute for Automation and Informatics (IAI) in Wernigerode, Germany, for its collaboration.

\section{References}

[1] G. Pandian and S. Rama Reddy, "Implementation of multilevel inverter-fed induction motor drive," Journal of Industrial Technology, vol. 24, no. 1, pp. 2-6, 2008.

[2] K. Yamanaka, A. M. Hava, H. Kirino, Y. Tanaka, N. Koga, and T. Kume, "A novel neutral point potential stabilization technique using the information of output current polarities and voltage vector," IEEE Transactions on Industry Applications, vol. 38, no. 6, pp. 1572-1580, 2002.

[3] Q. Song, W. Liu, Q. Yu, X. Xie, and Z. Wang, "A neutral-point potential balancing algorithm for three-level NPC inverters using analytically injected zero-sequence voltage," in Proceedings of the 18th Annual IEEE Applied Power Electronics Conference and Exposition, pp. 228-233, Miami Beach, Fla, USA, February 2003.

[4] H. Zhang, A. von Jouanne, S. Dai, A. K. Wallace, and F. Wang, "Multilevel inverter modulation schemes to eliminate commonmode voltages," IEEE Transactions on Industry Applications, vol. 36, no. 6, pp. 1645-1653, 2000.

[5] F. Z. Peng, "A generalized multilevel inverter topology with self voltage balancing," IEEE Transactions on Industry Applications, vol. 37, no. 2, pp. 611-618, 2001.
[6] J. Rodríguez, J. S. Lai, and F. Z. Peng, "Multilevel inverters: a survey of topologies, controls, and applications," IEEE Transactions on Industrial Electronics, vol. 49, no. 4, pp. 724-738, 2002.

[7] R. Bojoi, A. Tenconi, F. Profumo, G. Griva, and D. Martinello, "Complete analysis and comparative study of digital modulation techniques for dual three-phase AC motor drives," in Proceedings of the 33rd Annual IEEE Power Electronics Specialists Conference (PESC '02), vol. 2, pp. 851-857, Cairns, Australia, June 2002.

[8] D. Hadiouche, L. Baghli, and A. Rezzoug, "Space-vector PWM techniques for dual three-phase ac machine: analysis, performance evaluation, and DSP implementation," IEEE Transactions on Industry Applications, vol. 42, no. 4, p. 1112, 2006.

[9] J. Dixon and L. Morán, "A clean four-quadrant sinusoidal power rectifier using multistage converters for subway applications," IEEE Transactions on Industrial Electronics, vol. 52, no. 3, pp. 653-661, 2005.

[10] J. Dixon and L. Morán, "High-level multistep inverter optimization using a minimum number of power transistors," IEEE Transactions on Power Electronics, vol. 21, no. 2, pp. 330-337, 2006.

[11] P. K. Steimer and M. D. Manjrekar, "Practical medium voltage converter topologies for high power applications," in Proceedings of the IEEE Industrial Applications Society Annual Meeting, vol. 3, pp. 1723-1730, October 2001.

[12] J. Rodríguez, S. Bernet, B. Wu, J. O. Pontt, and S. Kouro, "Multilevel voltage-source-converter topologies for industrial medium-voltage drives," IEEE Transactions on Industrial Electronics, vol. 54, no. 6, pp. 2930-2945, 2007.

[13] R. Naderi and A. Rahmati, "Phase-shifted carrier PWM technique for general cascaded inverters," IEEE Transactions on Power Electronics, vol. 23, no. 3, pp. 1257-1269, 2008.

[14] M. S. A. Dahidah and V. G. Agelidis, "Selective harmonic elimination PWM control for cascaded multilevel voltage source converters: a generalized formula," IEEE Transactions on Power Electronics, vol. 23, no. 4, pp. 1620-1630, 2008.

[15] B. Ozpineci, Z. Du, L. M. Tolbert, and J. N. Chiasson, "Fundamental frequency switching strategies of a seven-level hybrid cascaded H-bridge multilevel inverter," IEEE Transactions on Power Electronics, vol. 24, no. 1, pp. 25-33, 2009.

[16] A. Nami, F. Zare, A. Ghosh, and F. Blaabjerg, "A hybrid cascade converter topology with series-connected symmetrical and asymmetrical diode-clamped H-bridge cells," IEEE Transactions on Power Electronics, vol. 26, no. 1, pp. 51-65, 2011.

[17] A. di Gaeta, L. Glielmo, V. Giglio, and G. Police, "Modeling of an electromechanical engine valve actuator based on a hybrid analytical-FEM approach," IEEE/ASME Transactions on Mechatronics, vol. 13, no. 6, pp. 625-637, 2008.

[18] J. Tsai, C. R. Koch, and M. Saif, "Camless engine," in Proceeding of the 47th IEEE Conference on Decision and Control, pp. 56895703, Cancun, Mexico, 2008.

[19] T. A. Parlikar, W. S. Chang, Y. H. Qiu et al., "Design and experimental implementation of an electromagnetic engine valve drive," IEEE/ASME Transactions on Mechatronics, vol. 10, no. 5, pp. 482-494, 2005.

[20] V. Hagenmeyer, Robust Nonlinear Tracking Control Based on Differential Flatness, Reihe 8 Nr. 978, Fortschritt-Berichte VDI, Düsseldorf, Germany, 2003.

[21] T. M. Rowan and D. W. Kerkman, "A new synchronous current regulator and an analysis of current regulated pwm inverters," in Proceedings of the IEEE Industry Applications Society Annual Meeting, 1985. 
[22] A. Bellini, S. Bifaretti, and S. Costantini, "Implementation on a microcontroller of a space vector modulation technique for NPC inverters," in Proceedings of the International IEEE Symposium on Industrial Electronics (IEEE-ISlE '04), pp. 935940, L’Aquila, Italy, May 2004.

[23] J. F. Martins, A. J. Pires, and J. F. Silva, "A Novel and simple current controller for three-phase IGBT PWM power invertersa comparative study," in Proceedings of the IEEE International Symposium on Industrial Electronics (IEEE-ISIE '97), pp. 241246, July 1997.

[24] J. Holtz and S. Stadtfeld, "A predictive controller for the stator current vector of ac machines fed from a switched voltage source," in Proceedings of the International Power Electronics Conference (IPEC '83), pp. 1665-1675, Tokio, Japan, 1983.

[25] H. le Huy and L. A. Dessaint, "An adaptive current control for pwm inverters," in Proceedings of the of IEEE Power Electronics Specialists Conference (PESC '86), 1986.

[26] R. Kennel and D. Schrder., "Predictive control strategy for converters," in Proceedings of the 3rd IFAC Symposium on Control in Power Electronics and Electrical Drives, pp. 415-422, Losanne, Switzerland, 1983.

[27] R. Teodorescu, F. Blaabjerg, J. K. Pedersen, E. Cengelci, and P. N. Enjeti, "Multilevel inverter by cascading industrial VSI," IEEE Transactions on Industrial Electronics, vol. 49, no. 4, pp. 832-838, 2002.

[28] Z. Ye, P. K. Jain, and P. C. Sen, "A full-bridge resonant inverter with modified phase-shift modulation for high-frequency AC power distribution systems," IEEE Transactions on Industrial Electronics, vol. 54, no. 5, pp. 2831-2845, 2007.

[29] Z. Ye, P. K. Jain, and P. C. Sen, "A two-stage resonant inverter with control of the phase angle and magnitude of the output voltage," IEEE Transactions on Industrial Electronics, vol. 54, no. 5, pp. 2797-2812, 2007.

[30] P. Cortes, A. Wilson, S. Kouro, J. Rodriguez, and H. AbuRub, "Model predictive control of multilevel cascaded H-bridge inverters," IEEE Transactions on Industrial Electronics, vol. 57, no. 8, pp. 2691-2699, 2010.

[31] K. A. Tehrani, H. Andriatsioharana, I. Rasoanarivo, and F. M. Sargos, "A novel multilevel inverter model," in Proceedings of the 39th IEEE Annual Power Electronics Specialists Conference (PESC '08), pp. 1688-1693, June 2008.

[32] A. Bemporad, M. Morari, V. Dua, and E. N. Pistikopoulos, "The explicit linear quadratic regulator for constrained systems," Automatica, vol. 38, no. 1, pp. 3-20, 2002.

[33] A. Bemporad and M. Morari, "Control of systems integrating logic, dynamics, and constraints," Automatica, vol. 35, no. 3, pp. 407-427, 1999.

[34] C. Pedret, A. Poncet, K. Stadler et al., "Model-varying predictive control of a nonlinear system," Internal Report in Computer Science Department, ETSE de la Universitat Autònoma de Barcelona, 2000.

[35] H. Sunan, T. K. Kiong, and L. T. Heng, Applied Predictive Control, Springer, London, UK, 2002.

[36] P. Mercorelli, N. Kubasiak, and S. Liu, "Multilevel bridge governor by using model predictive control in wavelet packets for tracking trajectories," in Proceedingsof the IEEE International Conference on Robotics and Automation, vol. 4, pp. 4079-4084, May 2004.

[37] N. Kubasiak, P. Mercorelli, and S. Liu, "Model predictive control of transistor pulse converter for feeding electromagnetic valve actuator with energy storage," in Proceedings of the 44th IEEE
Conference on Decision and Control, and the European Control Conference (CDC-ECC '05), pp. 6794-6799, December 2005. 

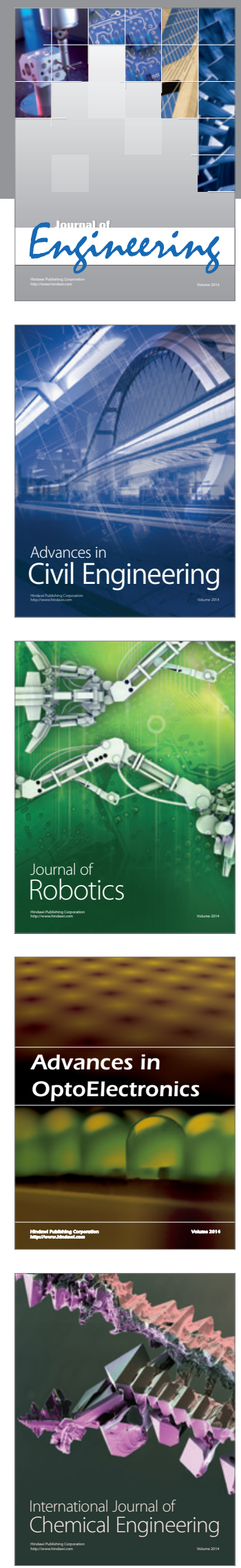

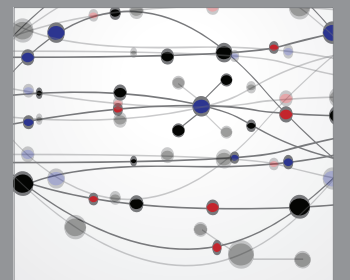

The Scientific World Journal
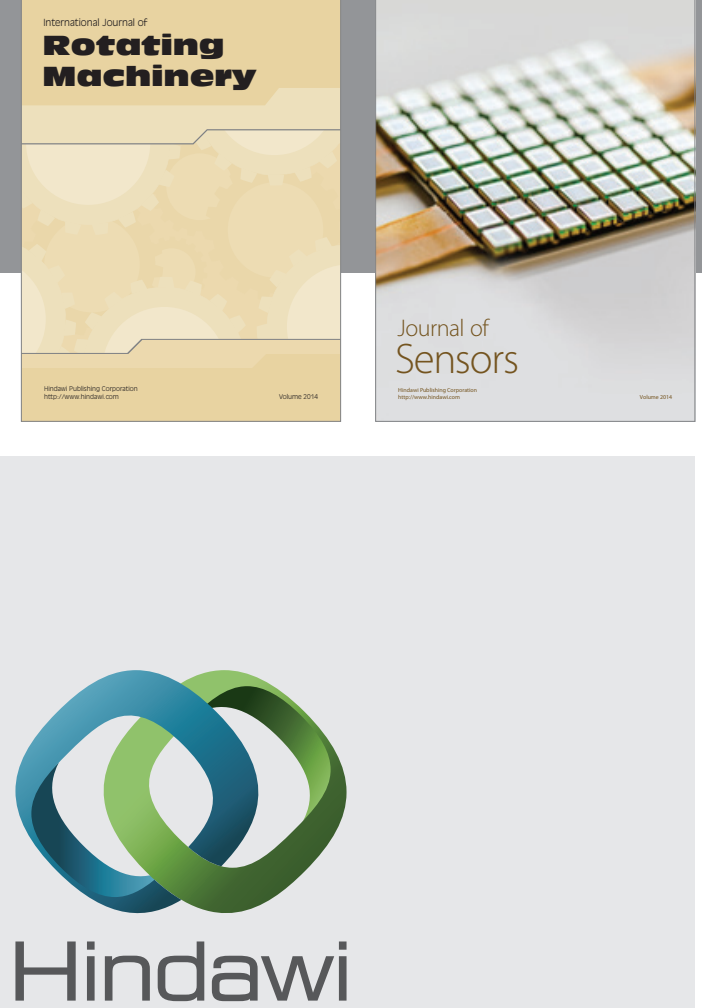

Submit your manuscripts at http://www.hindawi.com
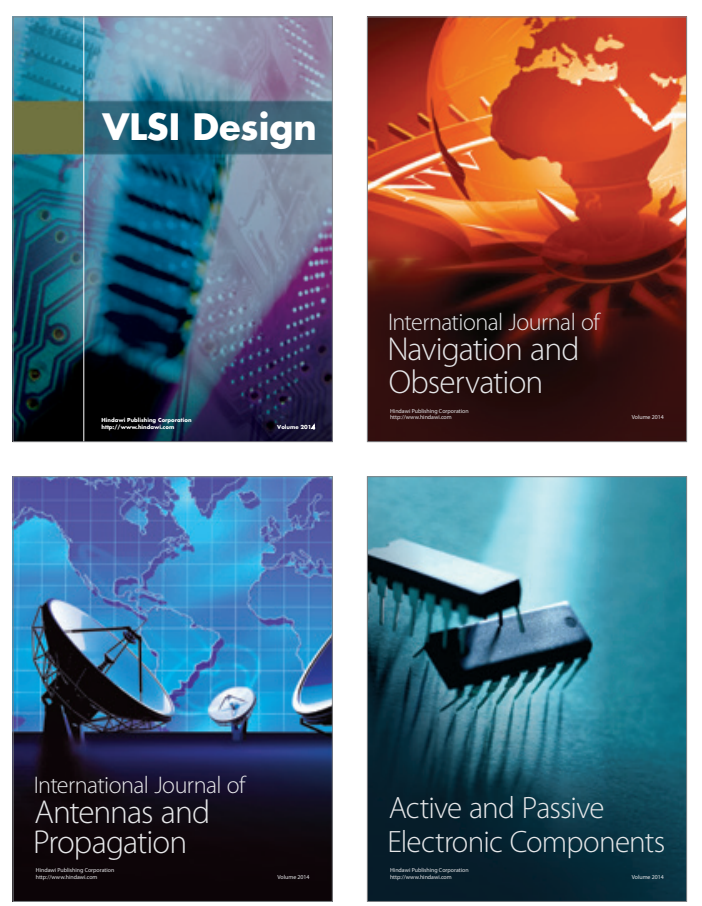
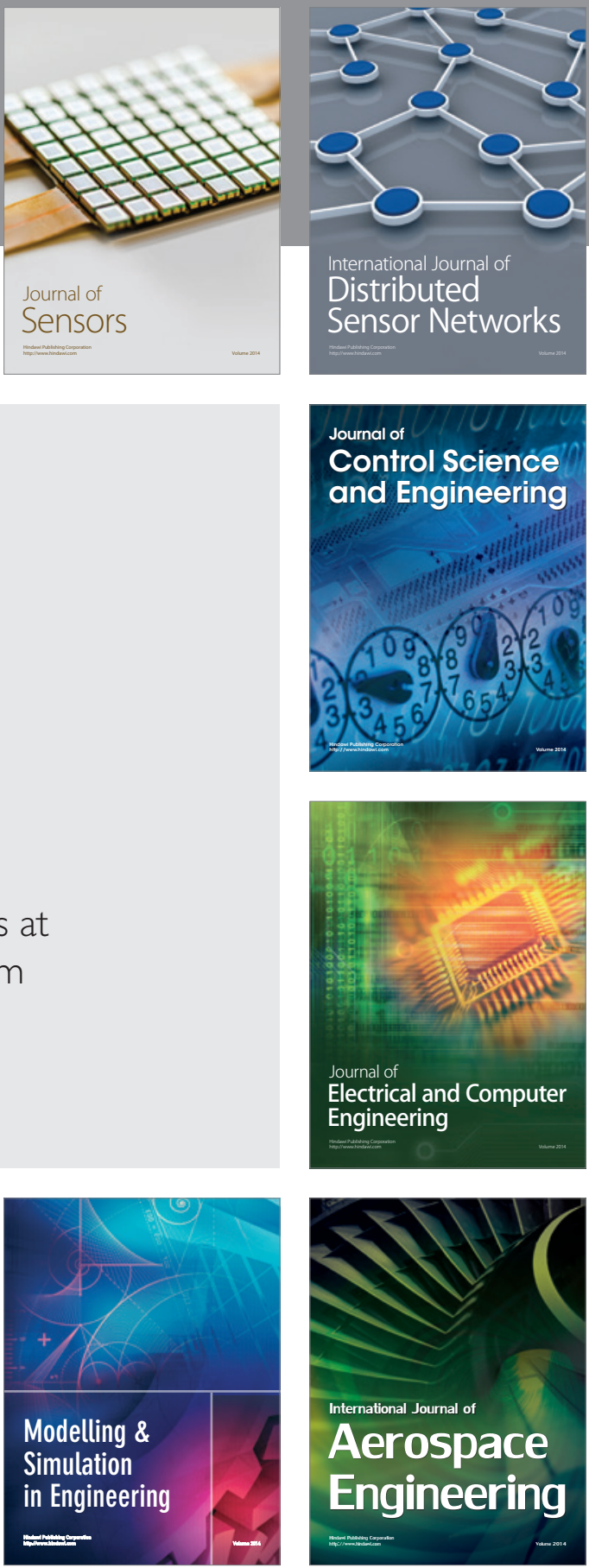

Journal of

Control Science

and Engineering
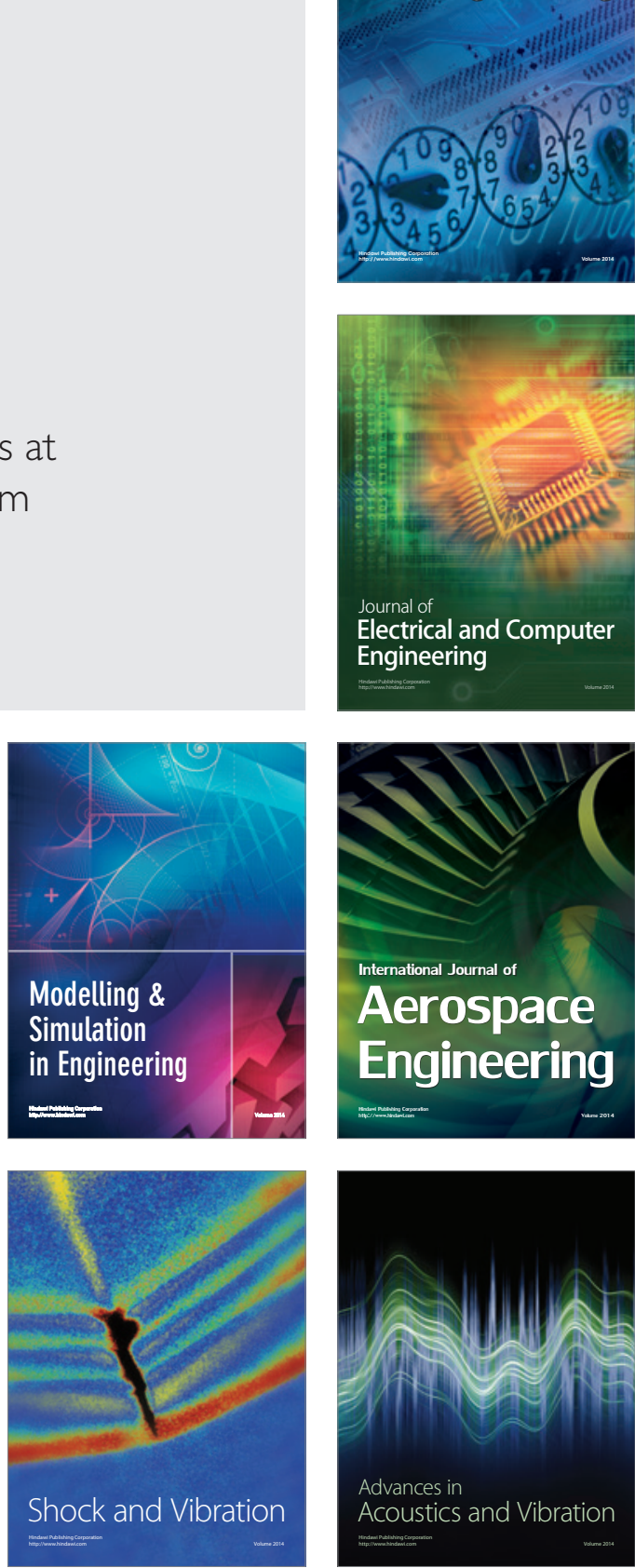